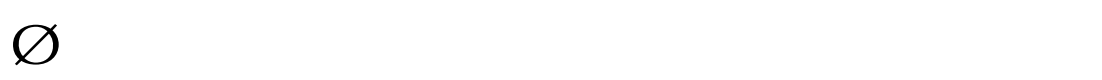

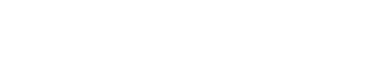

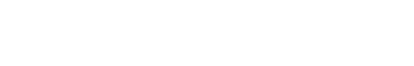

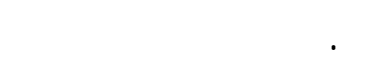

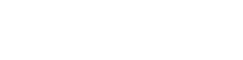

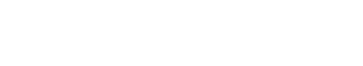

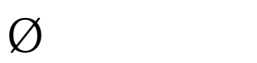

ŭ B̆̈̌̃̄ón

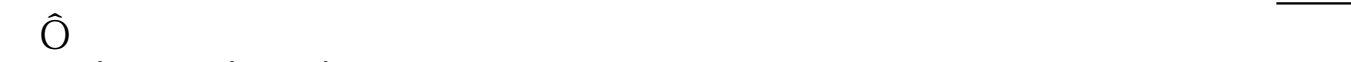

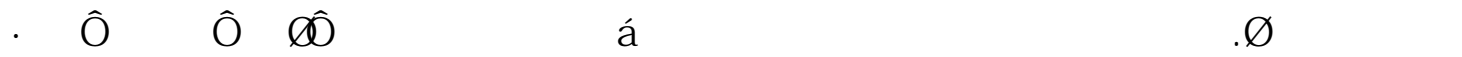

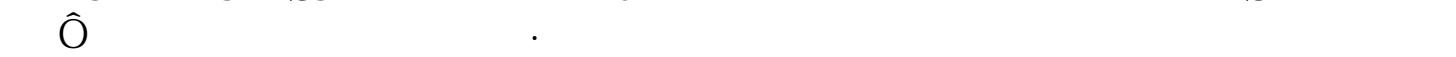

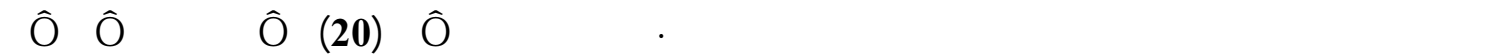

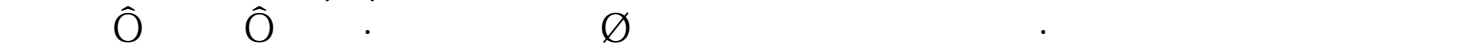

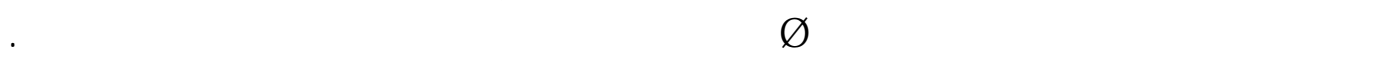

\section{Changing the Architectural Elements and it's Effect on Mosul Architecture}

\section{Dr. Abdullah Y. Al-Tayib Assistant Professor}

\section{Hafid Abid Yahya Al-Hiali} Master in Architecture

Department of Architecture University of Mosul

$\underline{\text { Abstract }}$

The research problem has been determined through the necessity of the architectural elements and determining their relations to one anther with the aim of studying the shifts that have been taken place in Mosul architecture. The research methodology encompasses the application of this frame to buildings that date back to the various stages of architectural change. Consequently, to find out change that have occurred in Mosul architecture elements and the diachronic relations which testify to either continuity or change in it. The research also embraces the method of collecting data on building samples. These include (20) building samples chosen according to objective criteria. Then, a case study on these samples has been applied using a special formula. In Consequence, results relating to the research hypothesis have testified, together with the finding, significant variance between the architectural phases through the changes that have taken place in the architectural elements.

Keyword: Mosul architecture, architectural stages and change. 


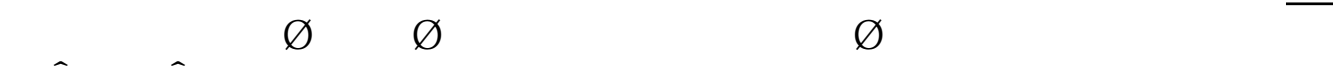

\section{rอtจ.1}

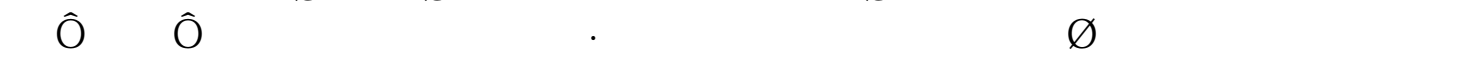

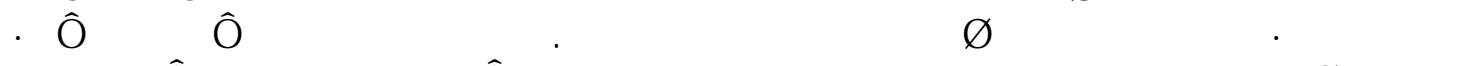

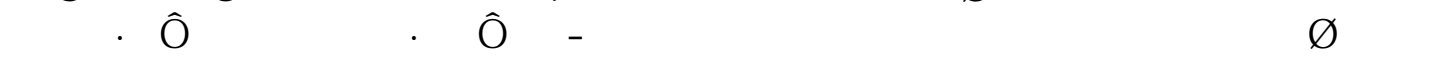
.

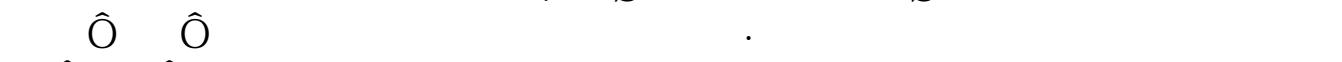

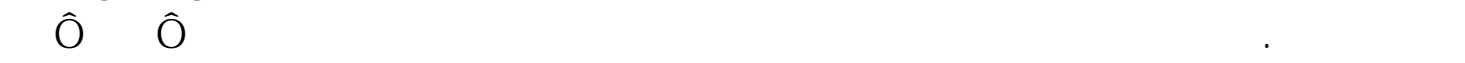

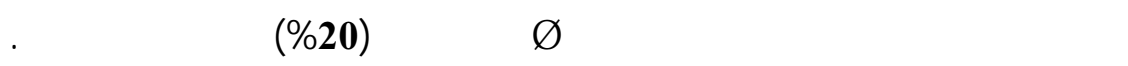

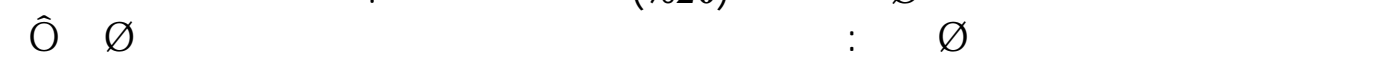

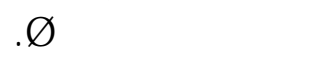

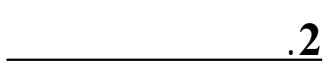

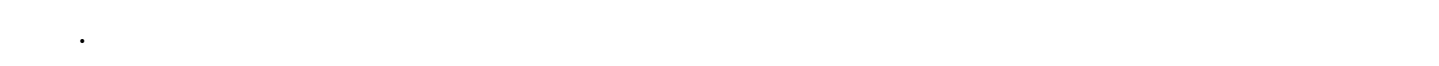

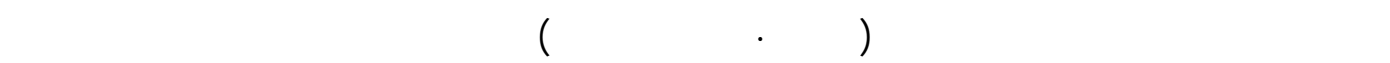

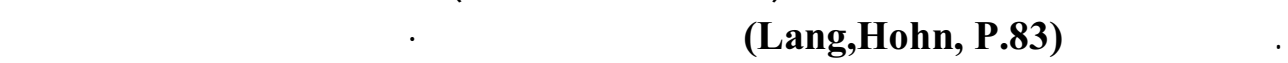

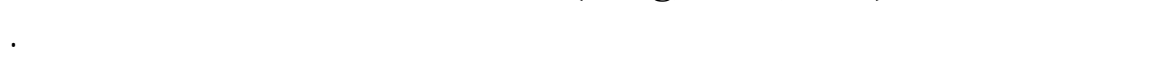

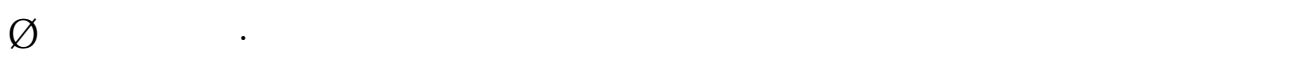

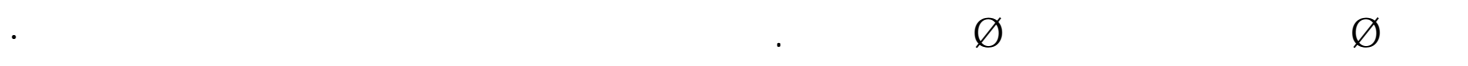

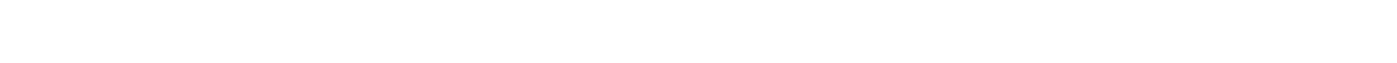

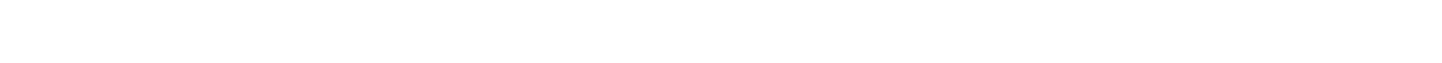

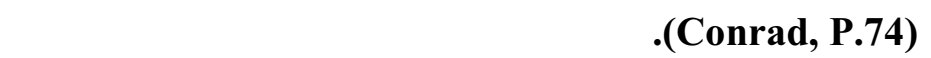

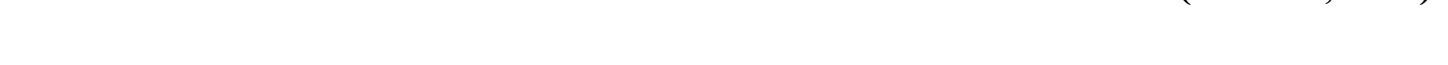

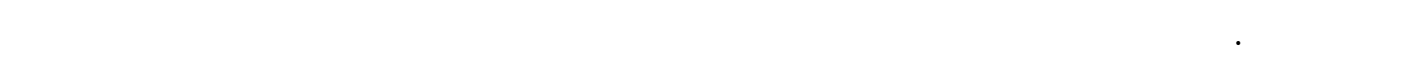

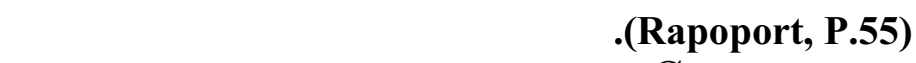

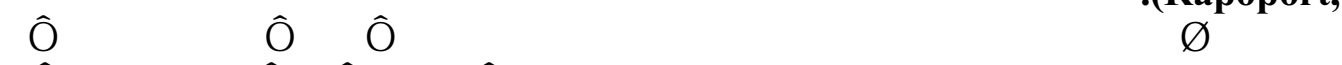

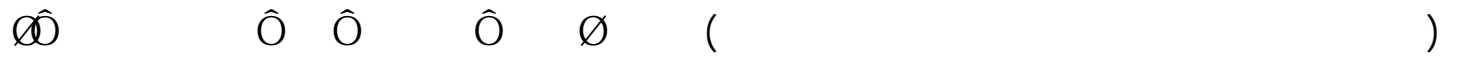

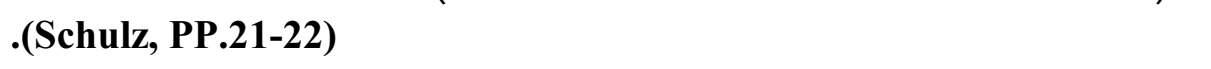

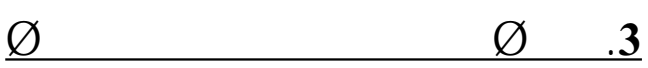

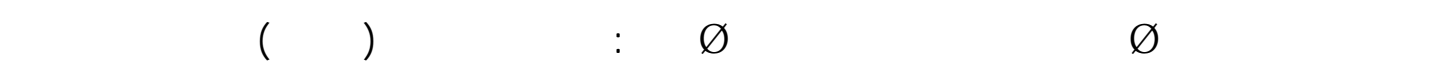

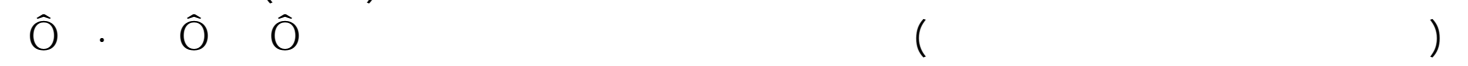

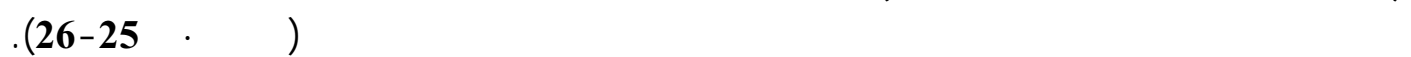

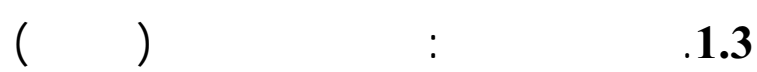

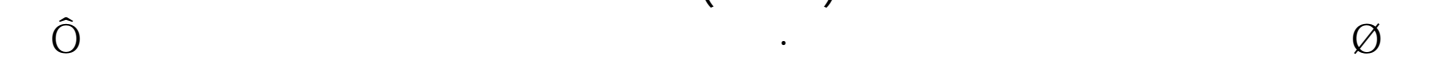

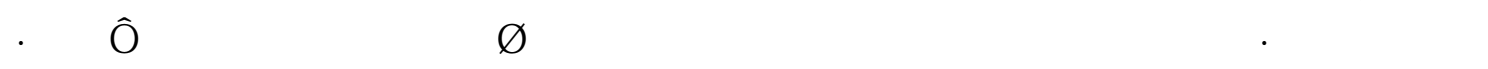

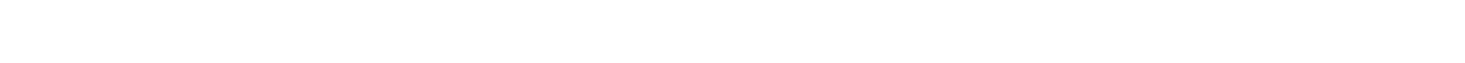

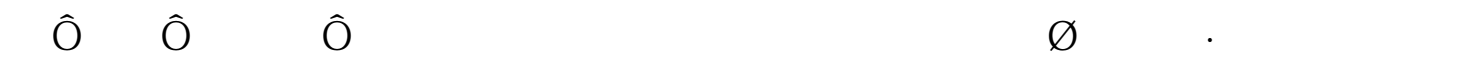

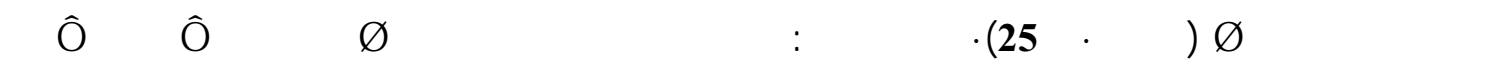

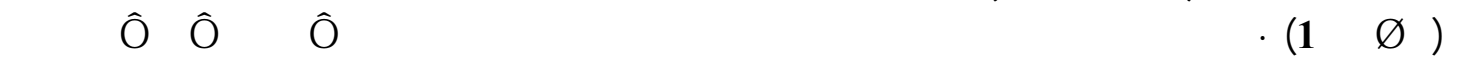

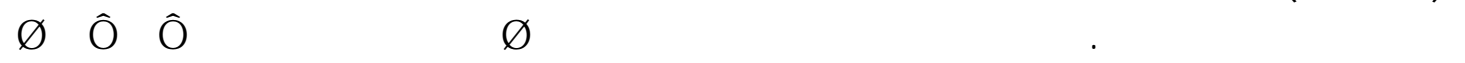

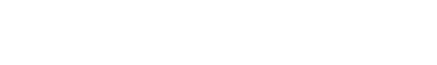




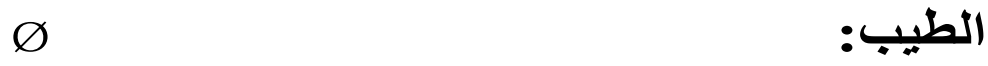

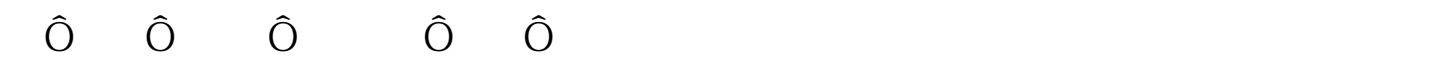

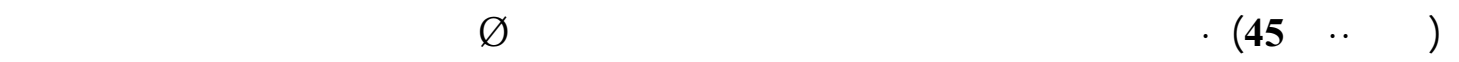

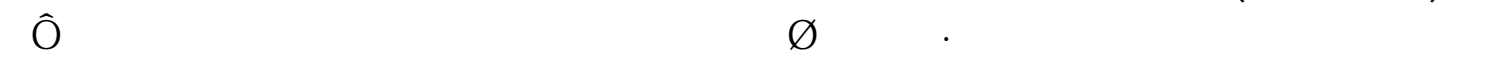

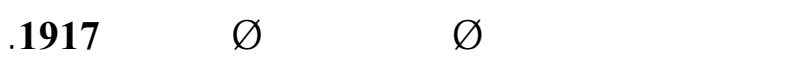

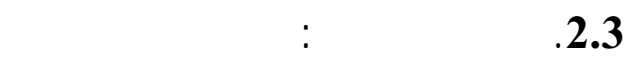

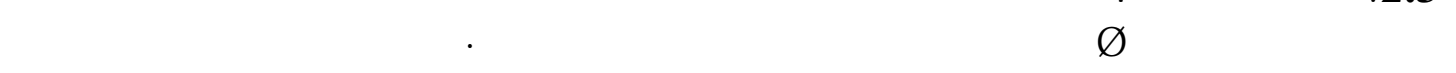

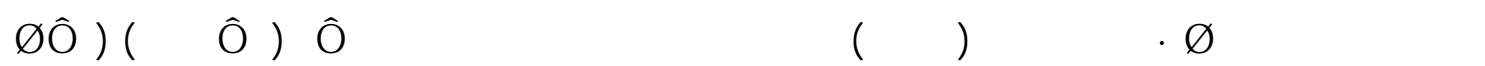

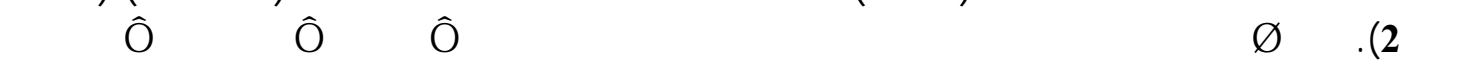

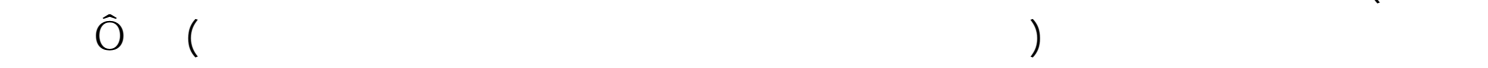

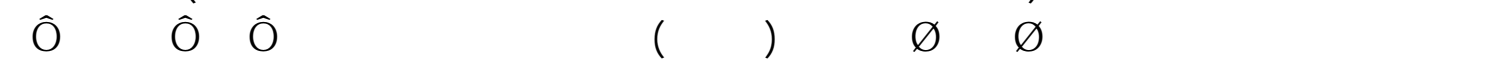

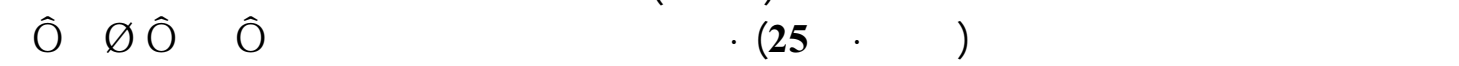

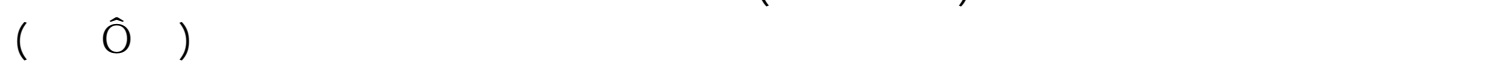

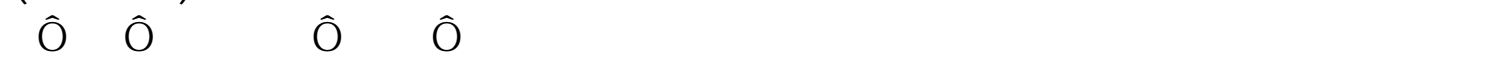

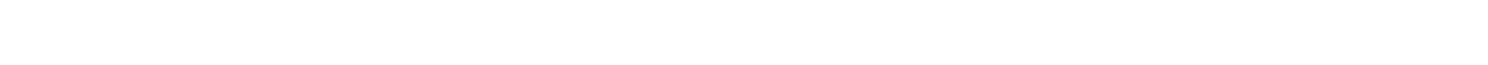

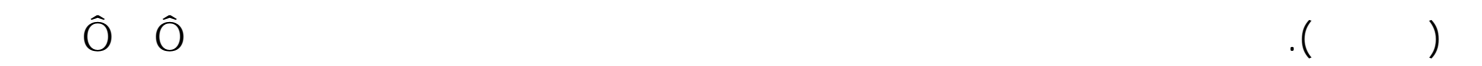

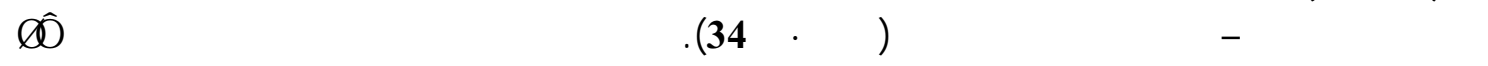

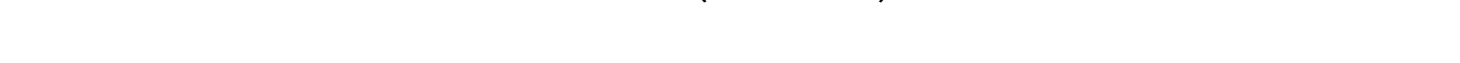

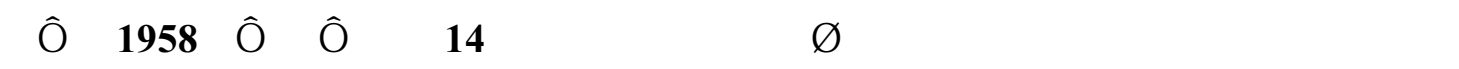

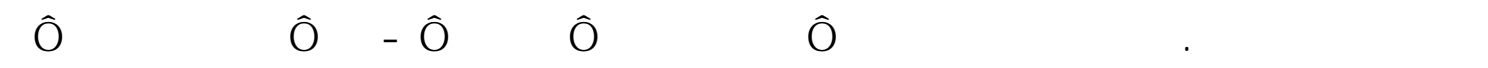

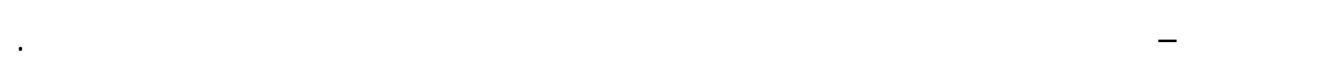

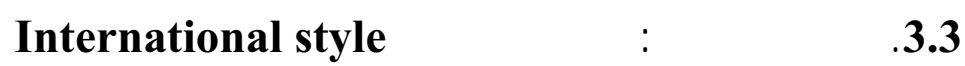

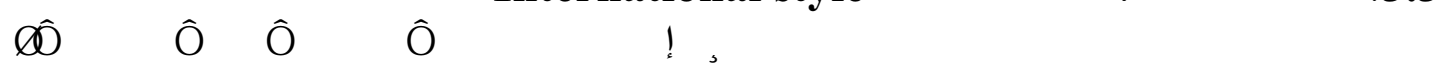

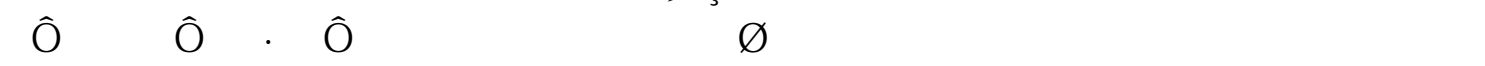

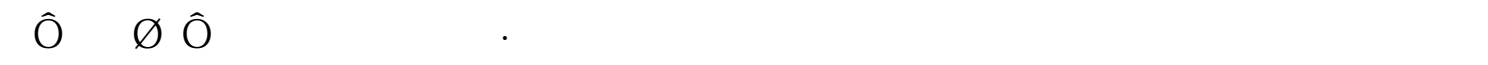

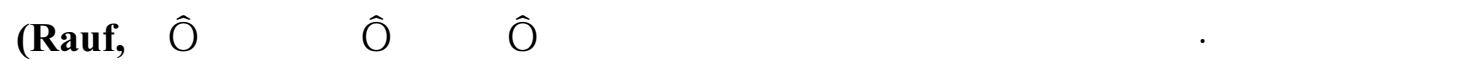
Fûßeว şh Ň

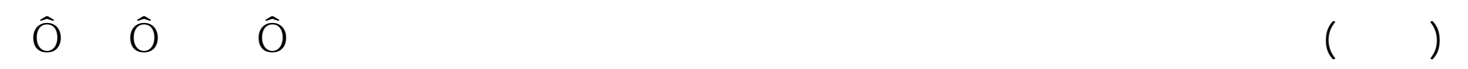

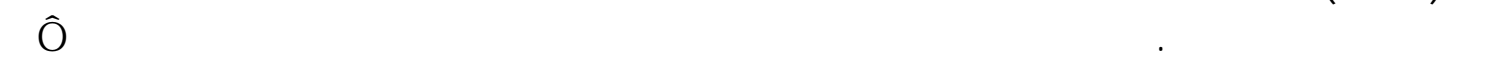

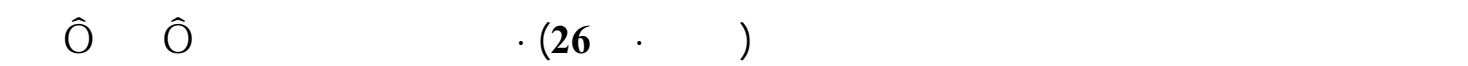

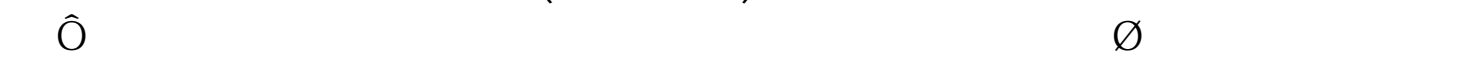

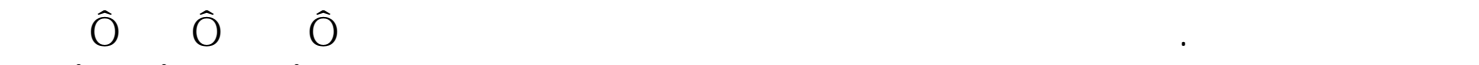

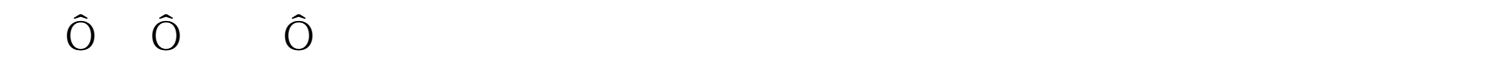

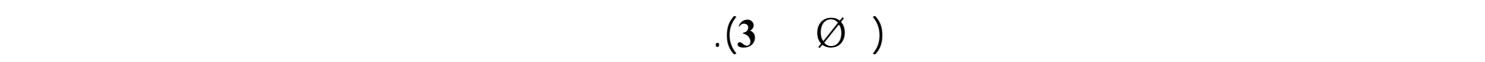

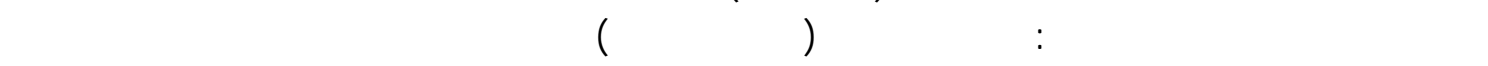

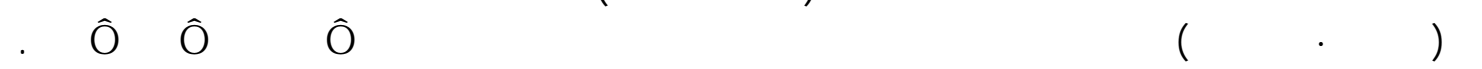

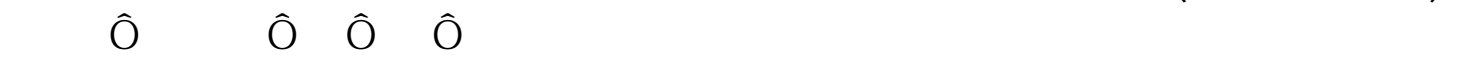

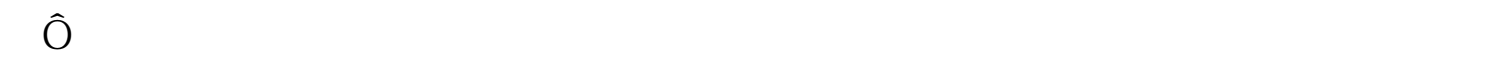




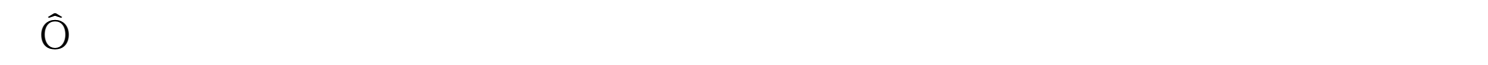
rrť́tJiea

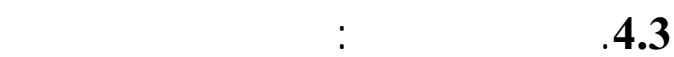

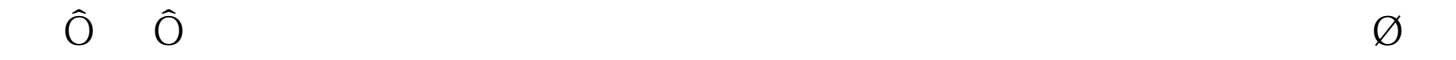

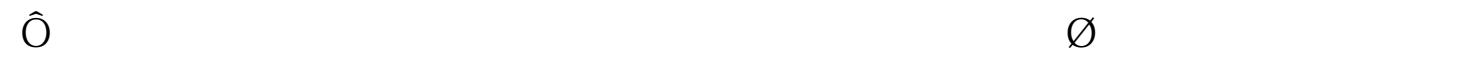

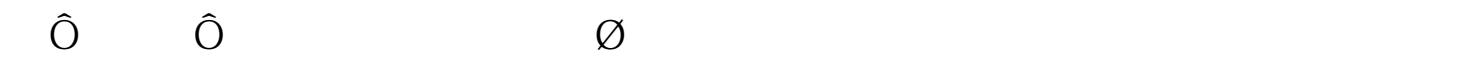

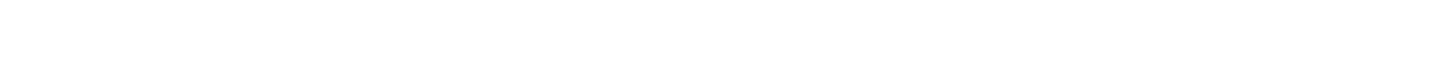

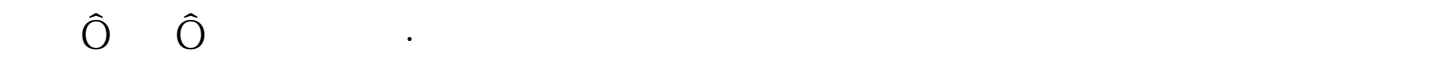

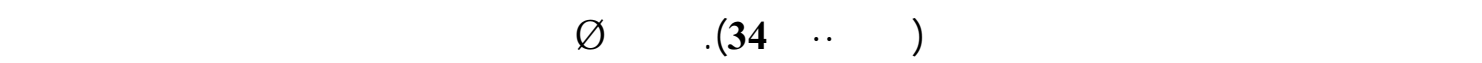

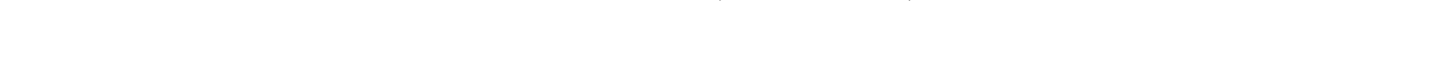

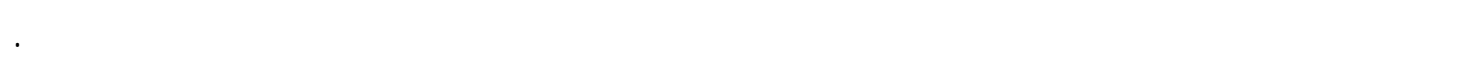

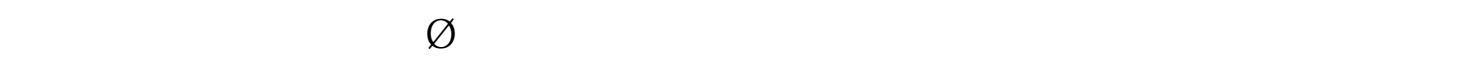

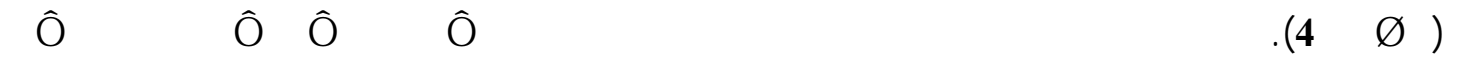

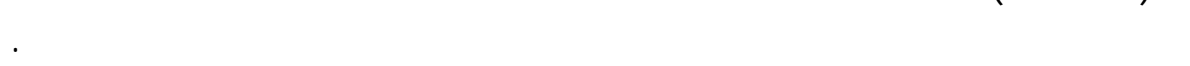

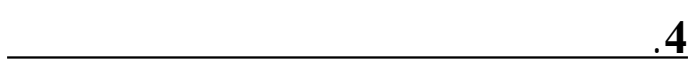

tŮ đ.

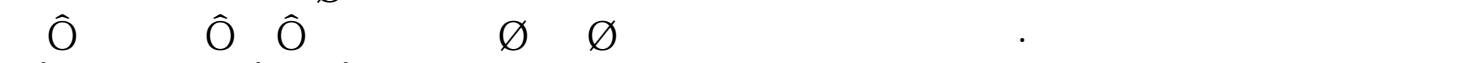

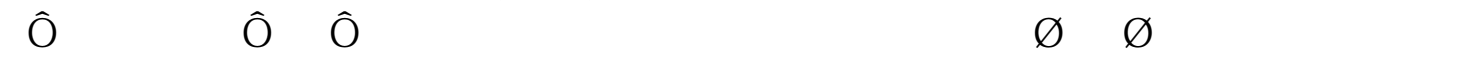

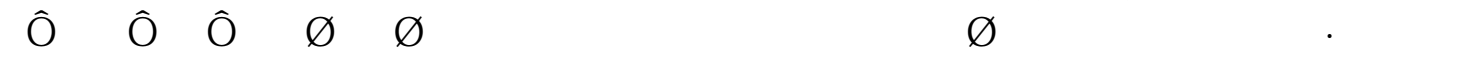

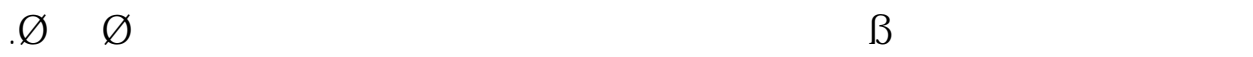

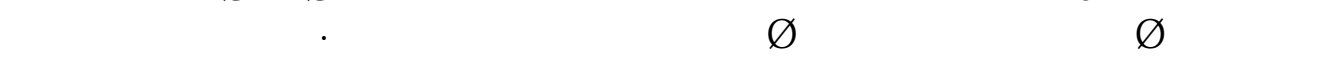

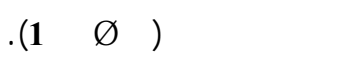

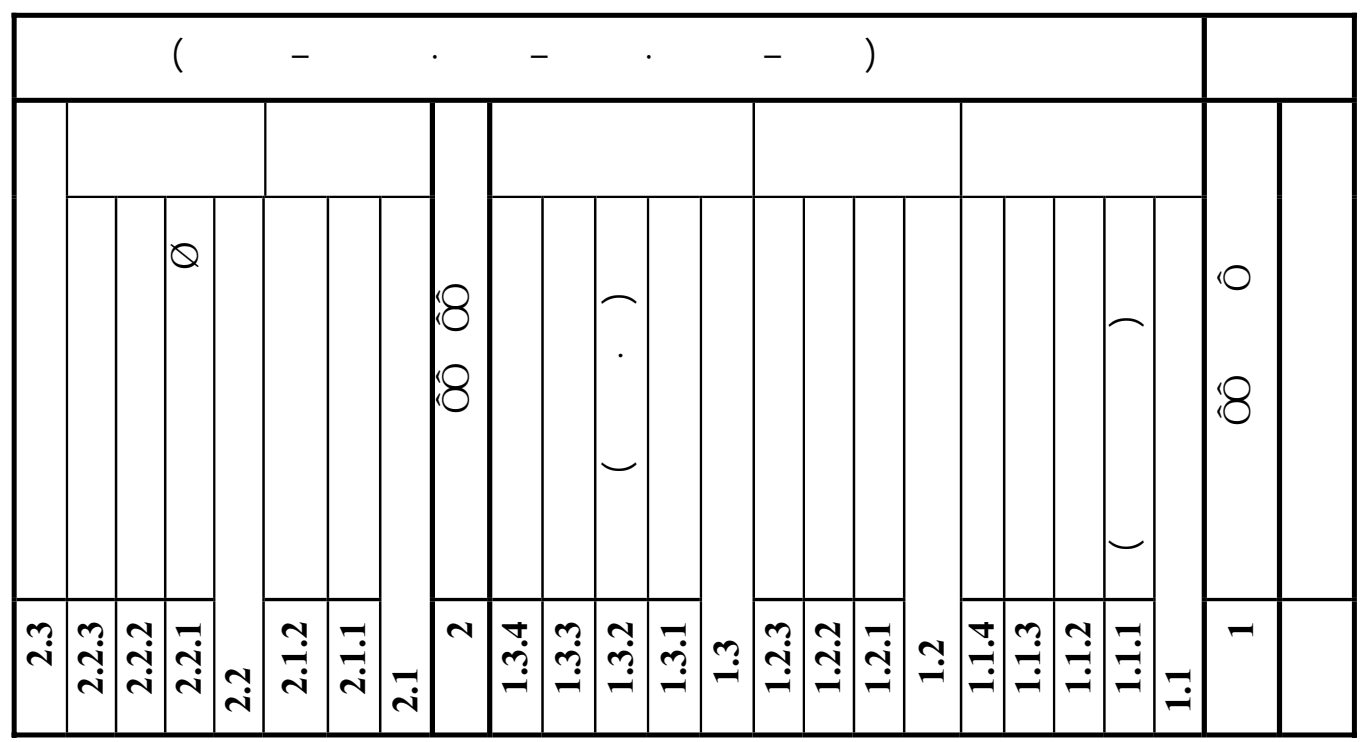

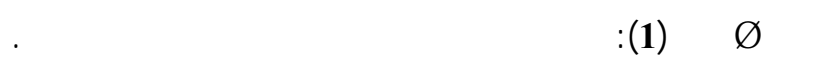




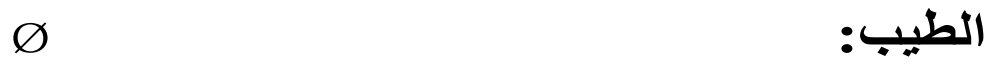

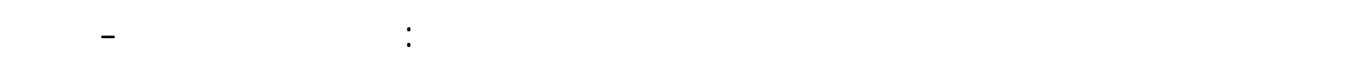

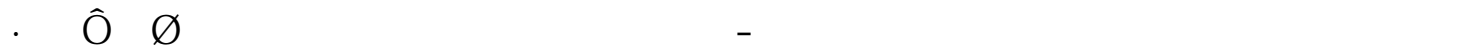

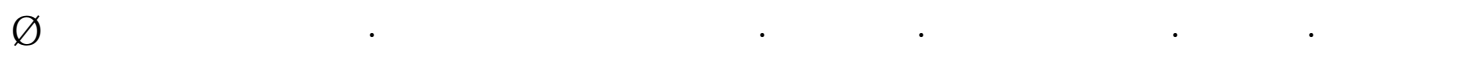

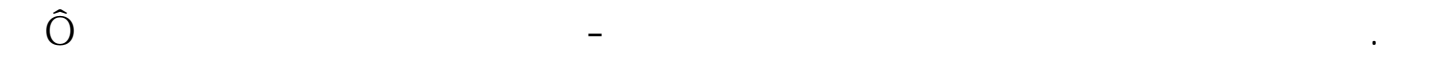

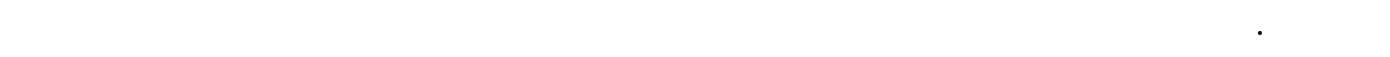

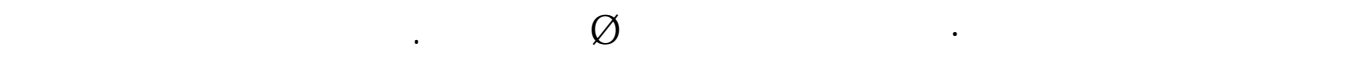
r̂̀ü Ređ

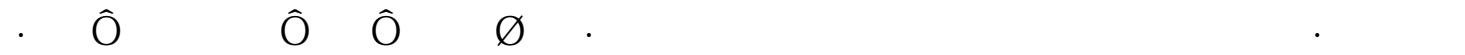
tof

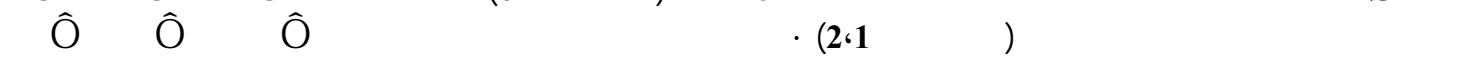

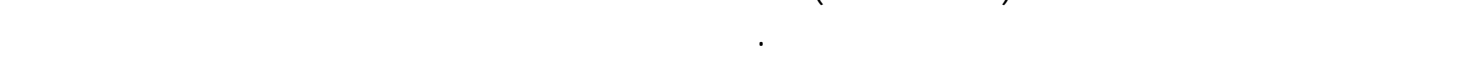

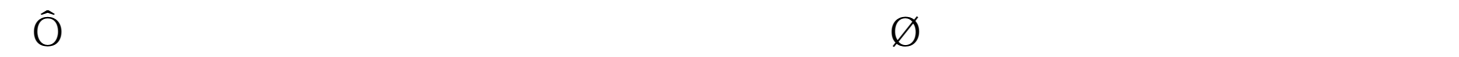

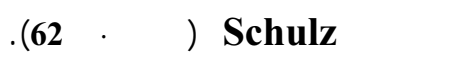
žfíüîts

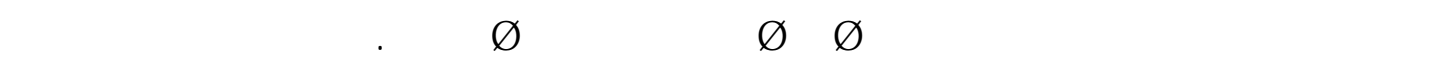

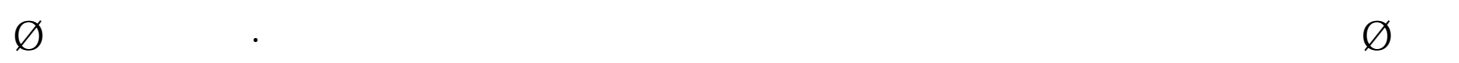

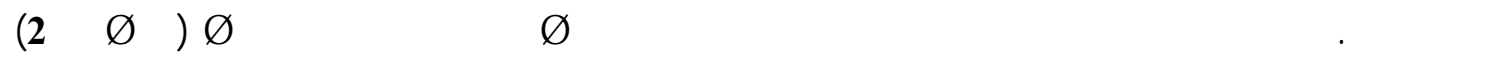

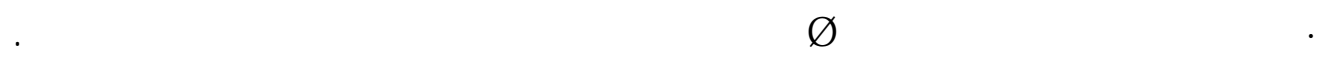

\begin{tabular}{|c|c|c|c|c|}
\hline 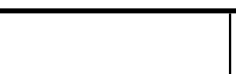 & V̂fơाE & 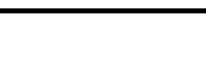 & rfी́ñ̄o & 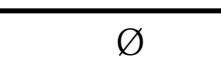 \\
\hline \multirow{5}{*}{ 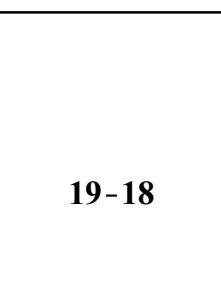 } & 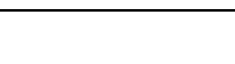 & If $\mathbf{f B J}$ & 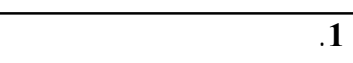 & \multirow{5}{*}{ 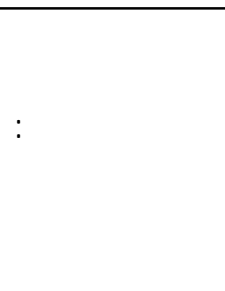 } \\
\hline & 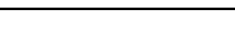 & n̂िgd & 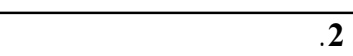 & \\
\hline & 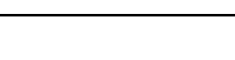 & 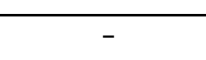 & 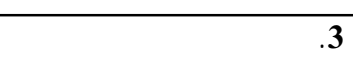 & \\
\hline & Ŕgüríáć & rftegr & 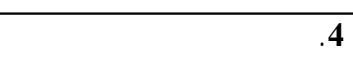 & \\
\hline & Ŕgüríáá & पfơt & 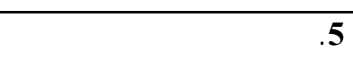 & \\
\hline \multirow{5}{*}{ 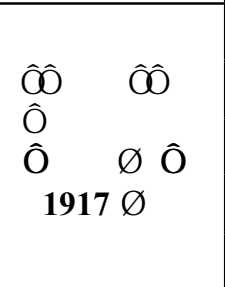 } & rūgthṬtón & Iffe & Ł过6 & \multirow{5}{*}{ 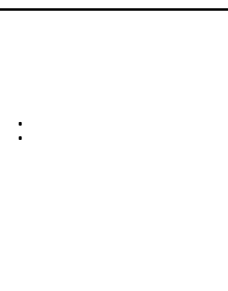 } \\
\hline & 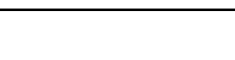 & !ftéb & 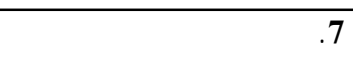 & \\
\hline & 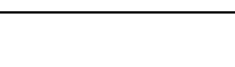 & !f & 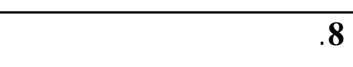 & \\
\hline & $\exists g f \hat{c} u t d \bar{l}$ & rftegr & 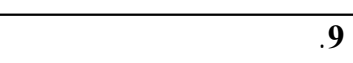 & \\
\hline & 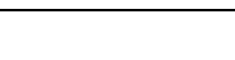 & पfơt & 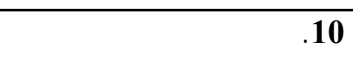 & \\
\hline \multirow{5}{*}{ 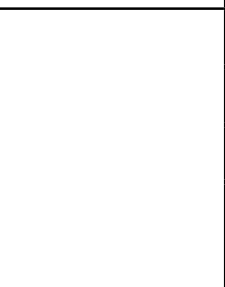 } & tgã్̃šš & Iffed & t定11 & \multirow{5}{*}{ 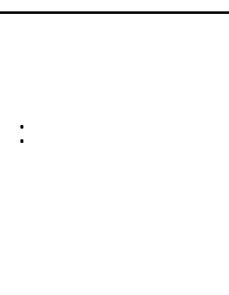 } \\
\hline & 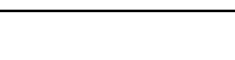 & 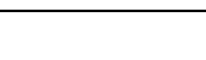 & 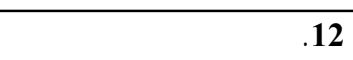 & \\
\hline & 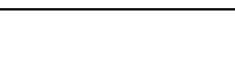 & 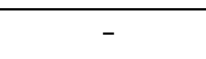 & 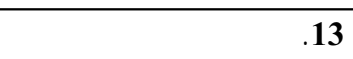 & \\
\hline & Ŕgüríá & Iftegr & 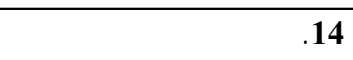 & \\
\hline & 2SREšs & Ifớt & 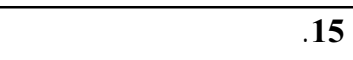 & \\
\hline \multirow{5}{*}{ 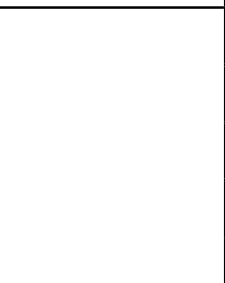 } & tgã్̃šs & Iffei & E进16 & \multirow{5}{*}{ 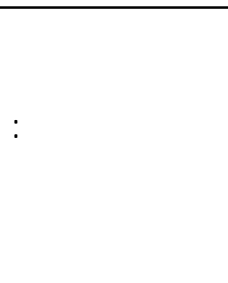 } \\
\hline & ทf & पfÉ & EgEDrystoft & \\
\hline & rügutratión & 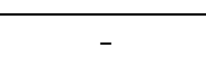 & 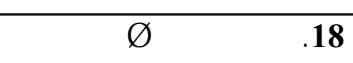 & \\
\hline & Ŕgứríá & rftegr & 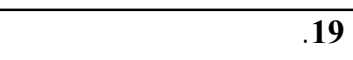 & \\
\hline & 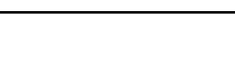 & पfर्भir & Ifoidiputetb.20 & \\
\hline
\end{tabular}




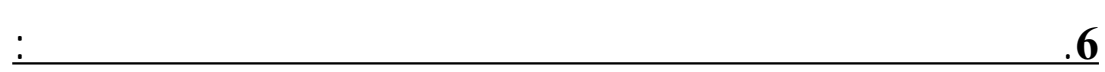

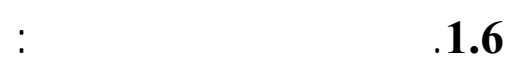

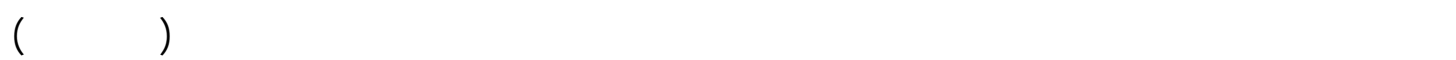

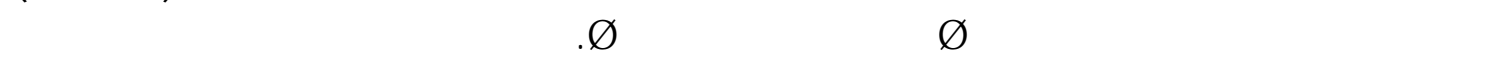

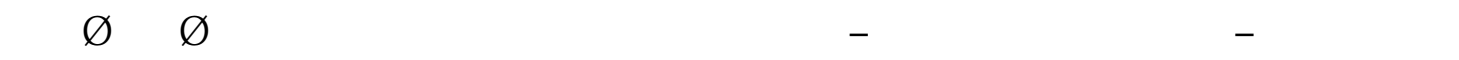
.r̂thofỡar

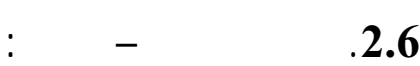

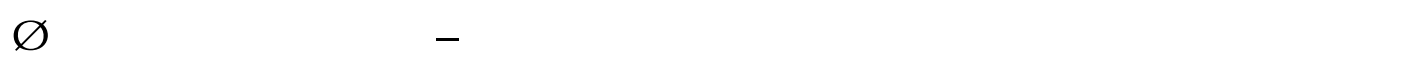

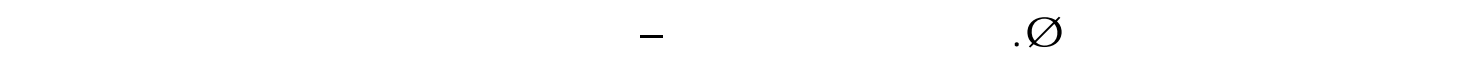

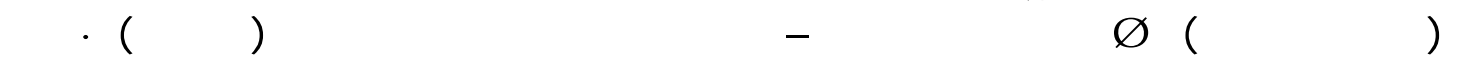

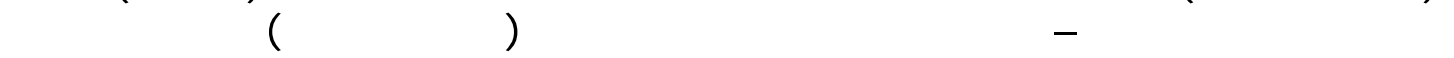

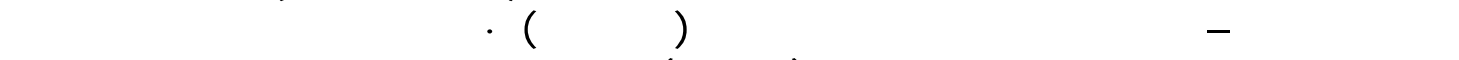

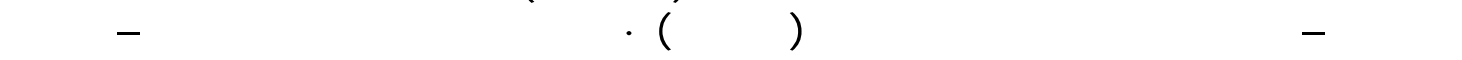

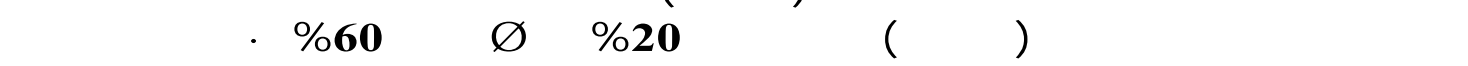

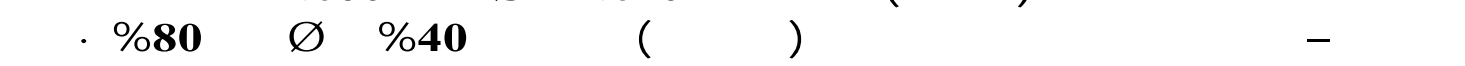

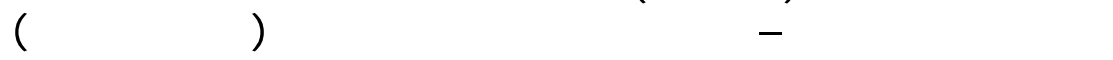

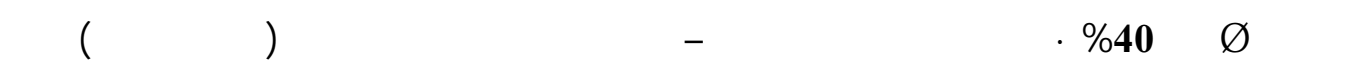

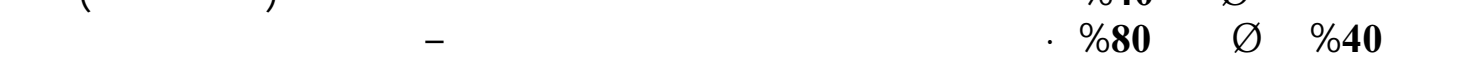

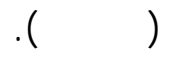

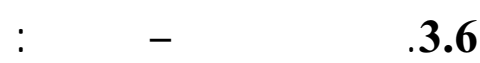

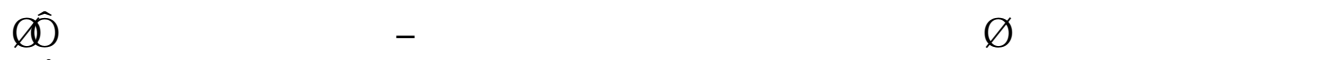

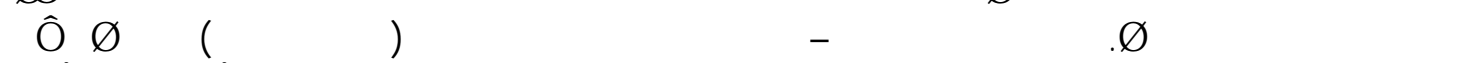

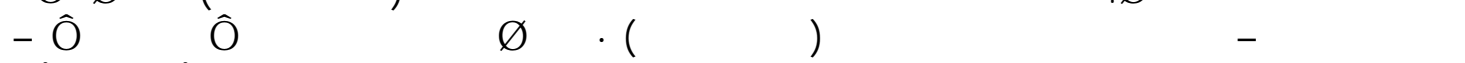

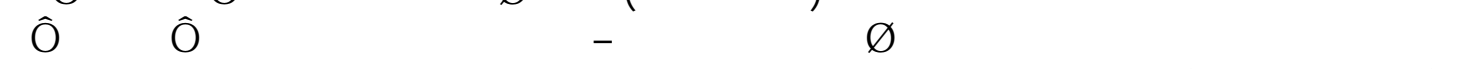

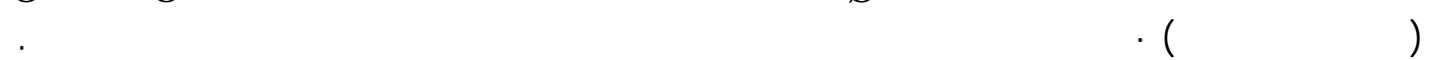

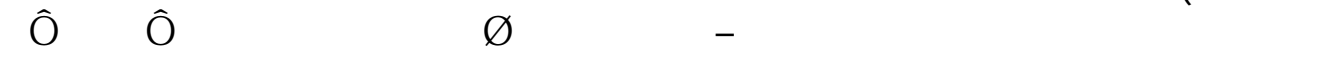

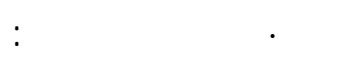

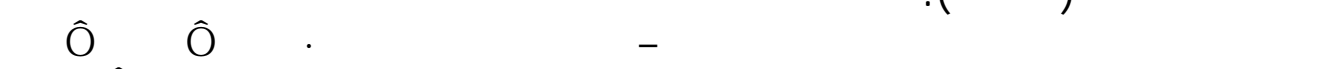

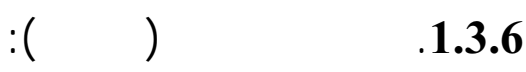
Żğ̋onog

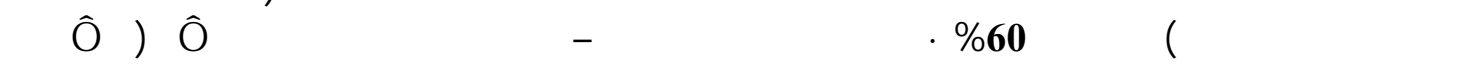

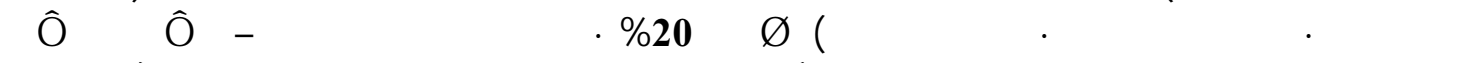

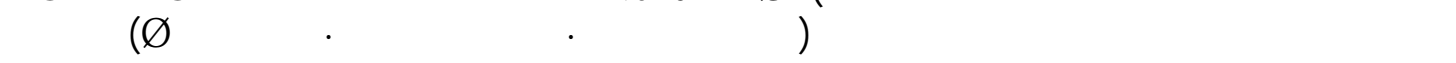

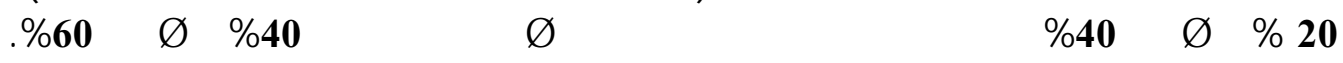

:(rfiñ

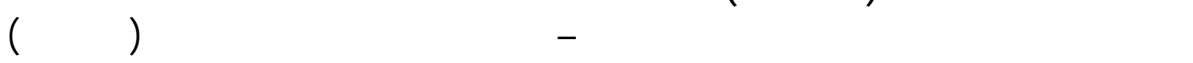

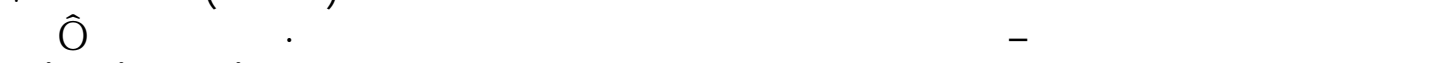

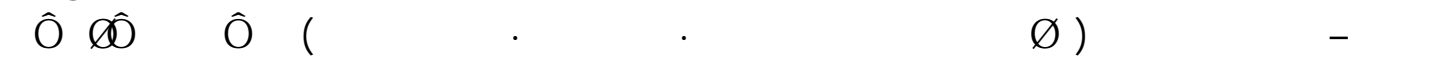

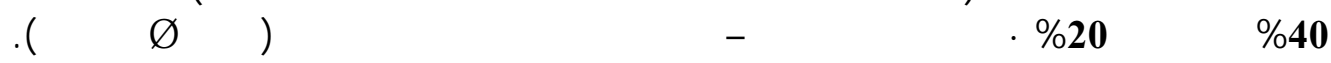


الطيب:

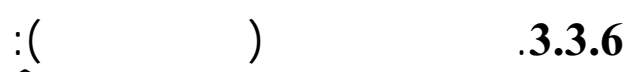

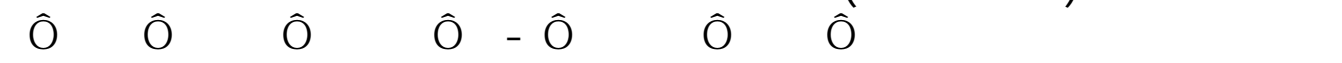

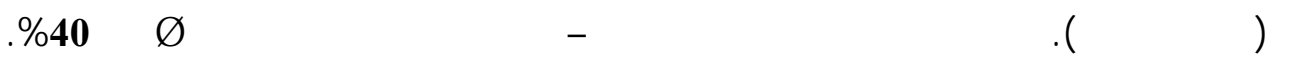

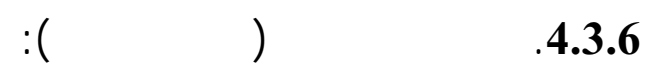

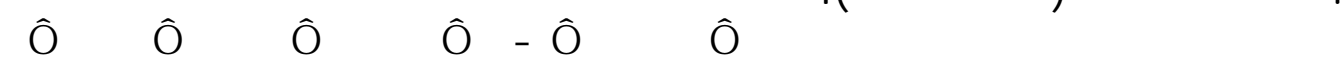

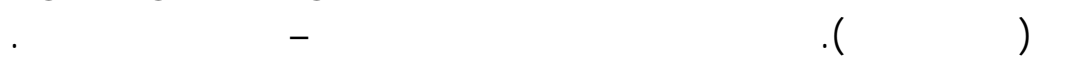

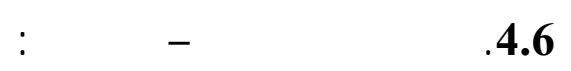

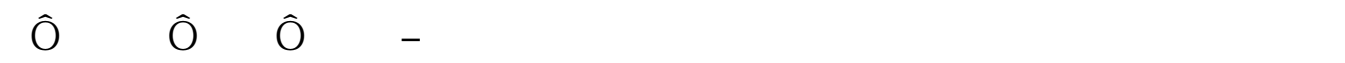

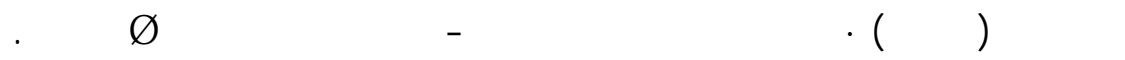

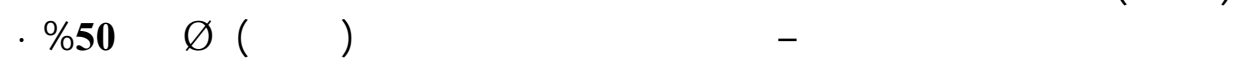

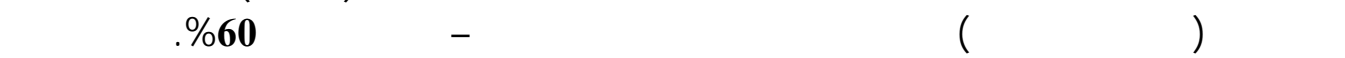

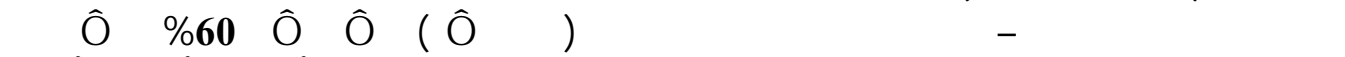

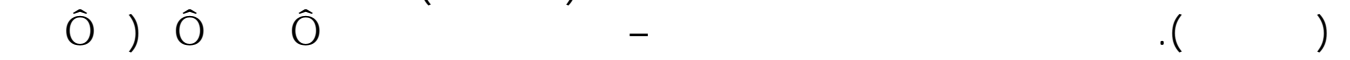

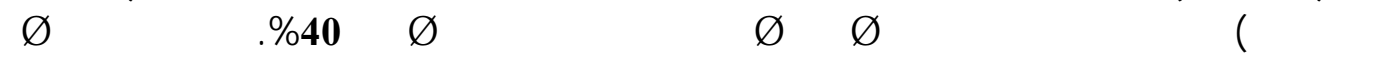

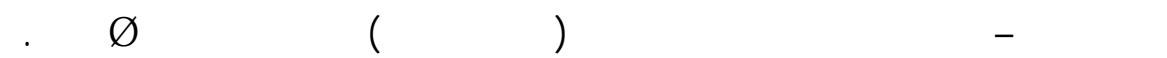

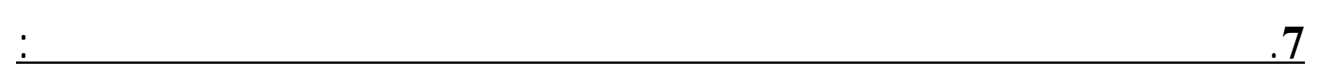

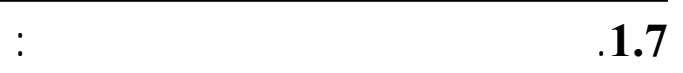

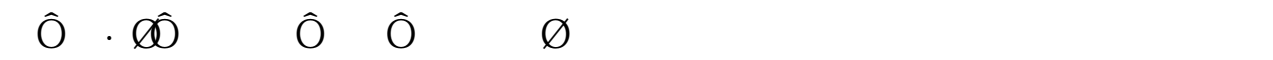

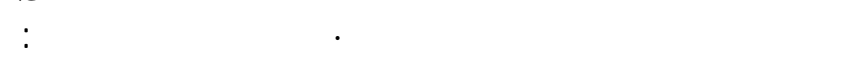

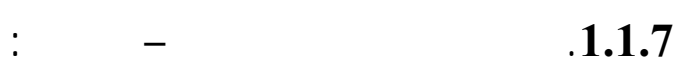

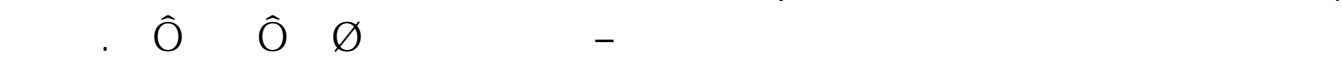

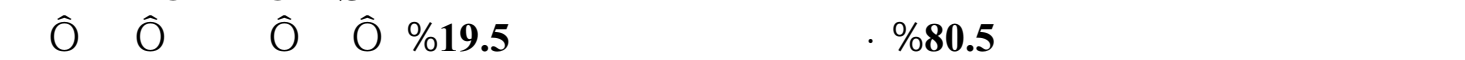

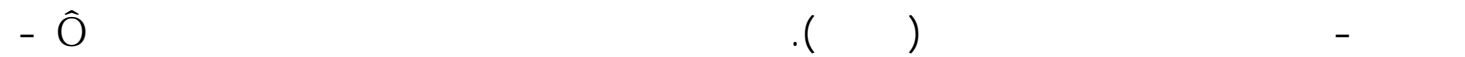

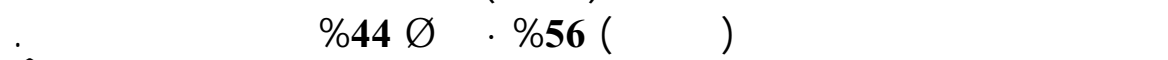

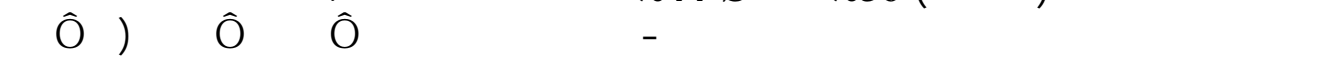

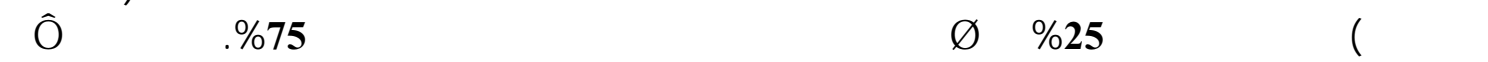

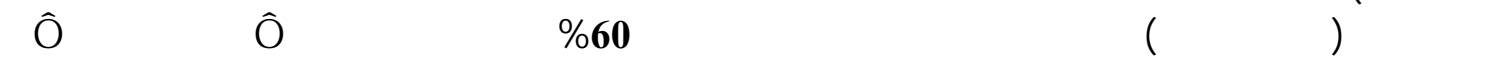

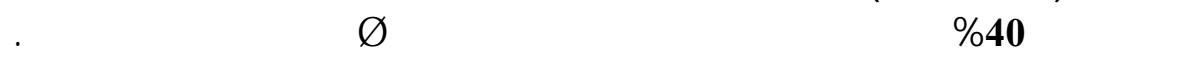

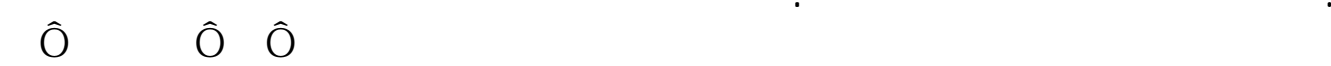

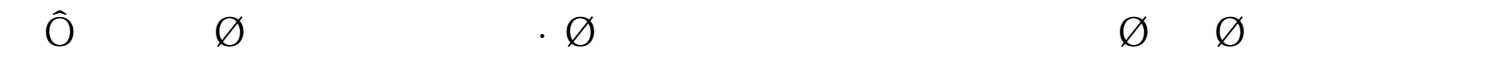

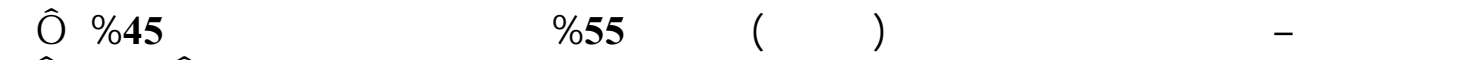

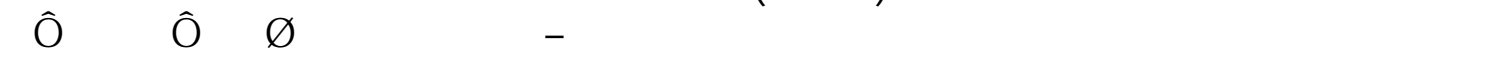

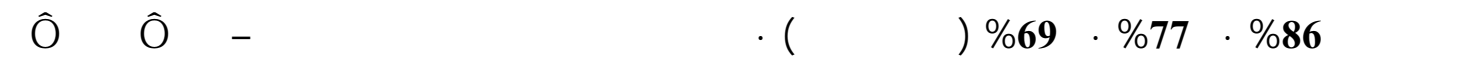

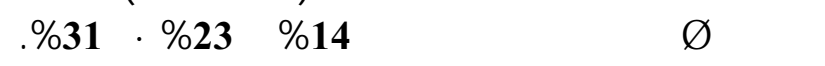




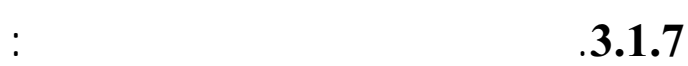

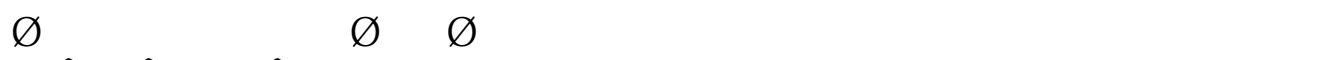

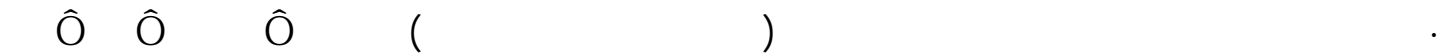

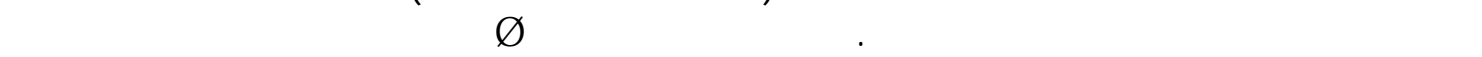

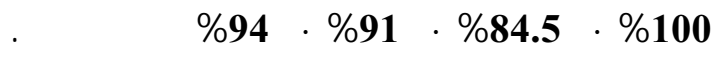

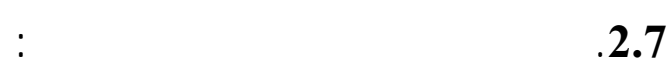

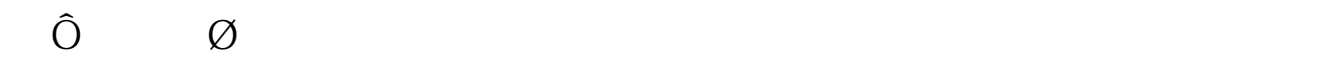

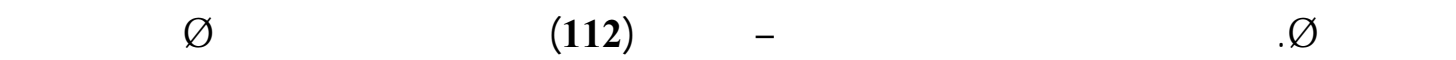

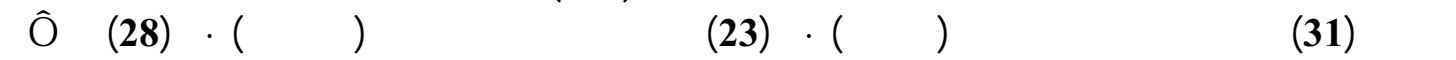

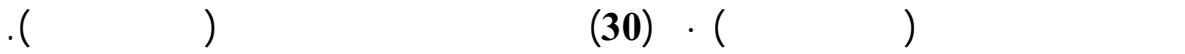

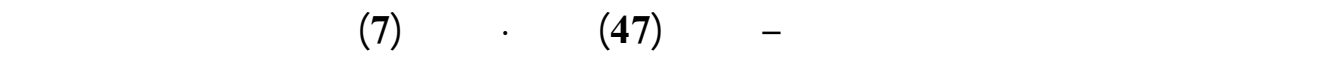

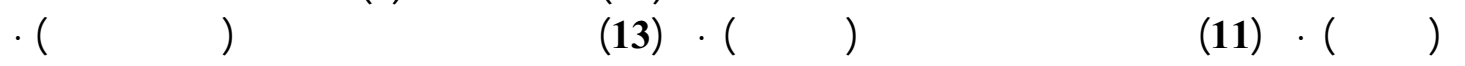

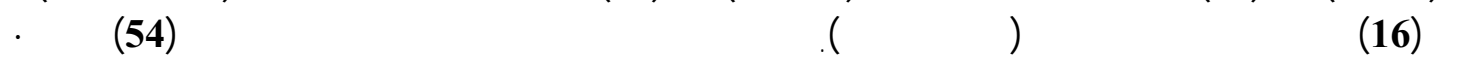

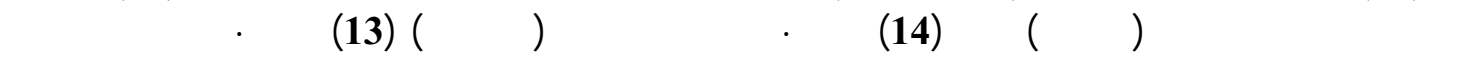

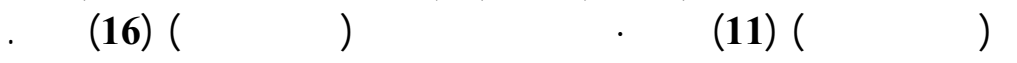

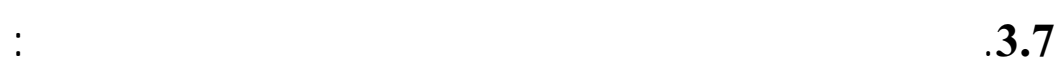

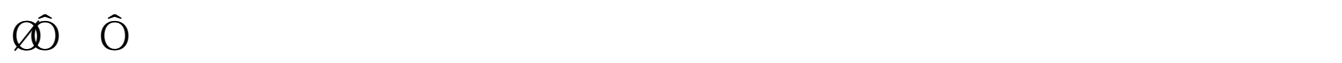

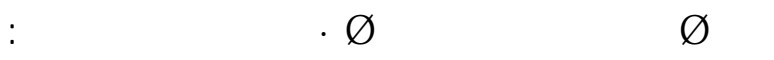

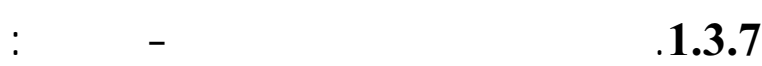

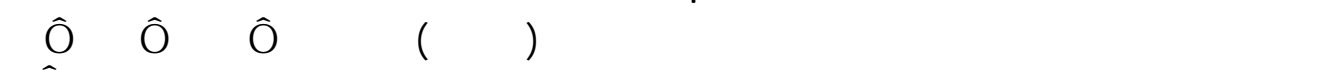

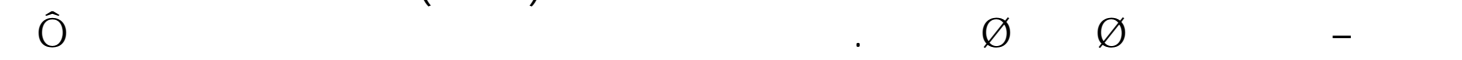

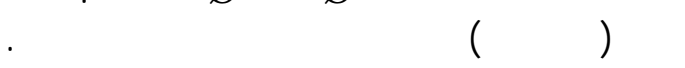

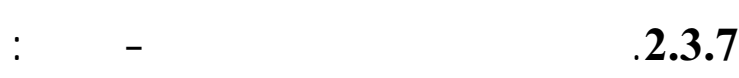

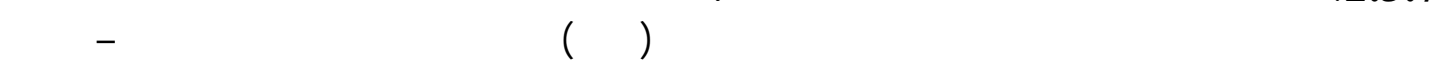

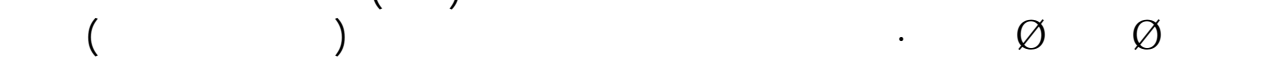

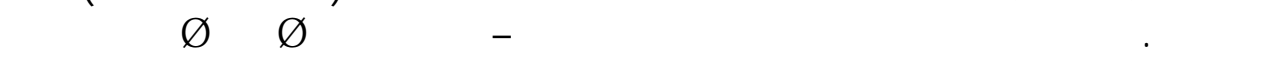

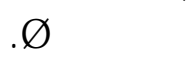

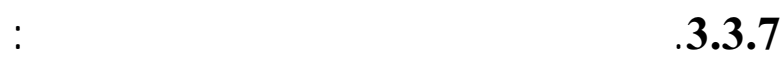

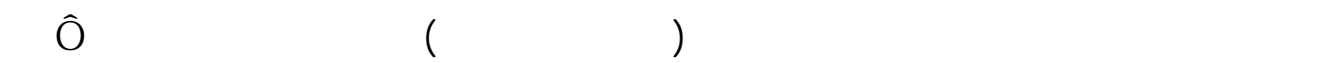

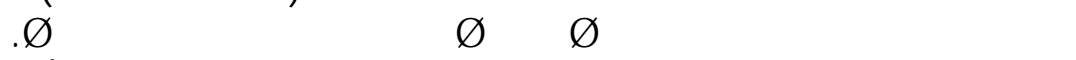

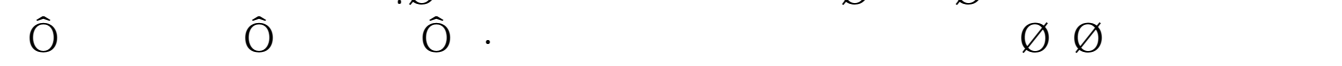

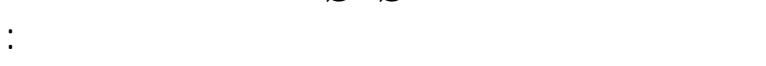

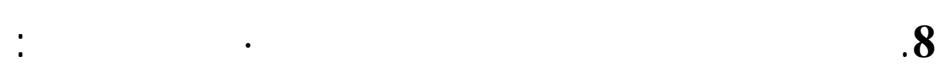

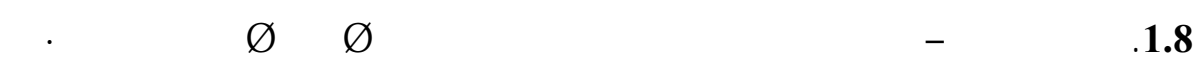

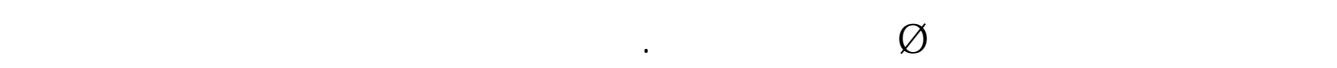




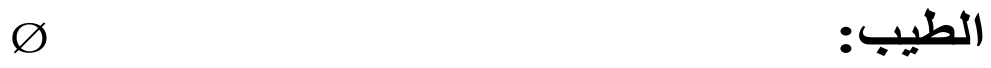

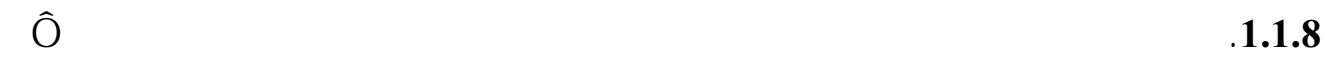

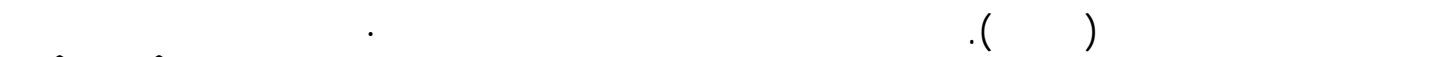

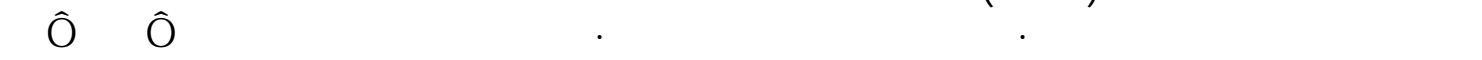

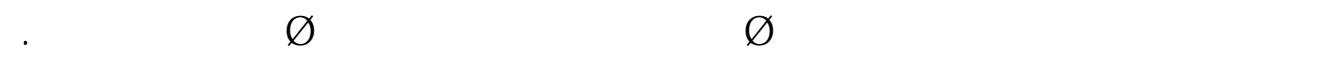

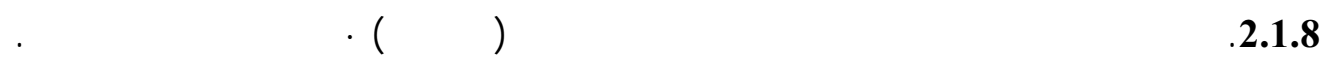

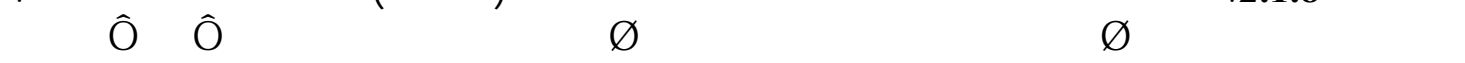

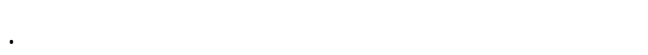

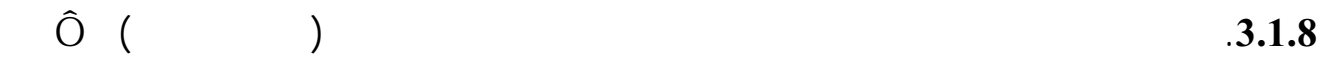

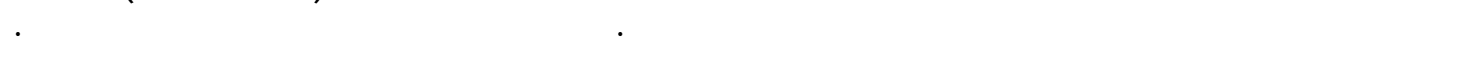

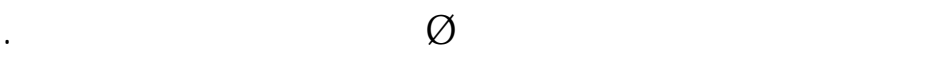

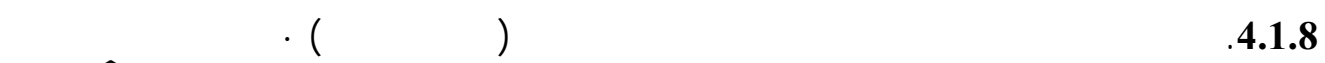

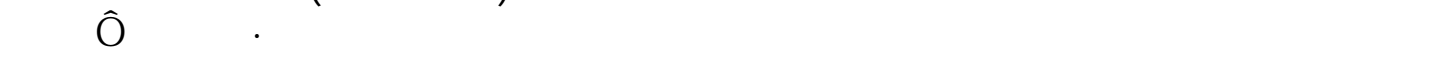
.

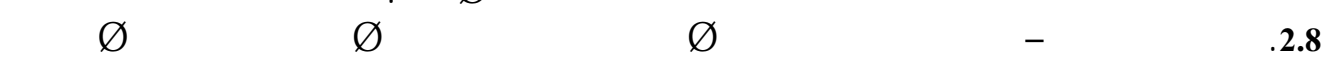

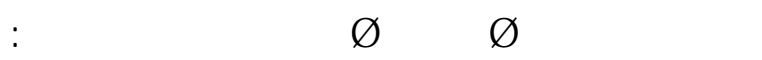

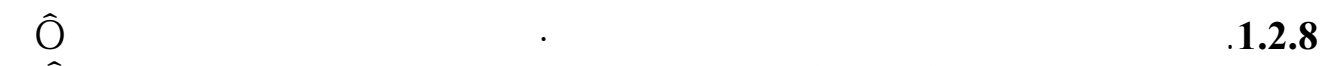

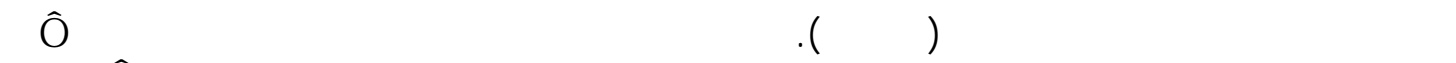

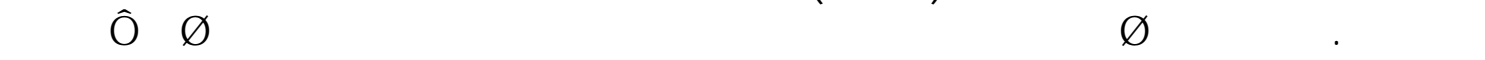

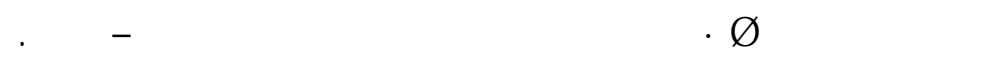

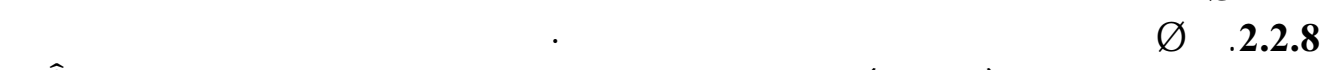

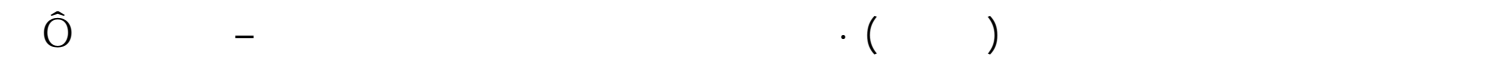

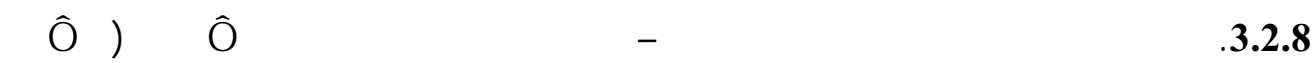

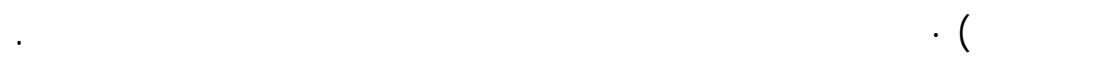

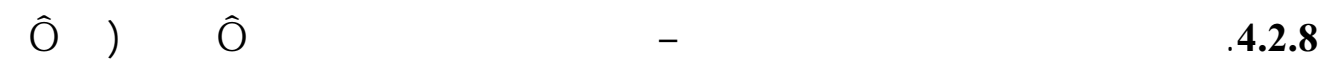

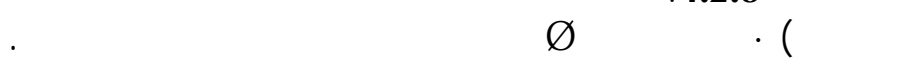

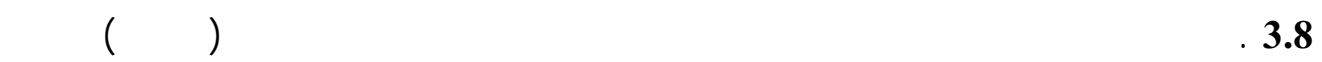

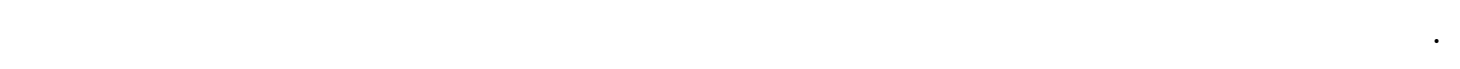

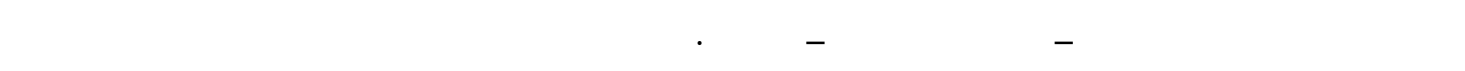

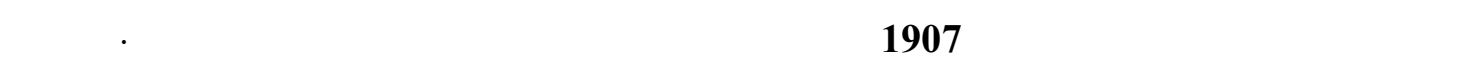

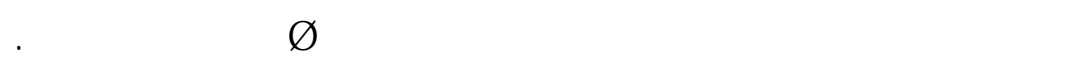

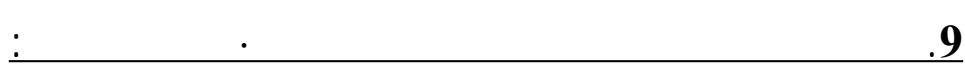

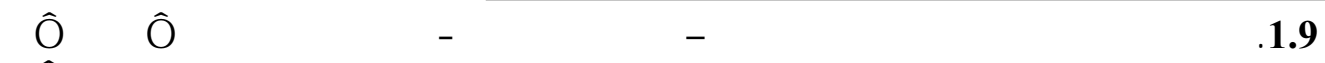

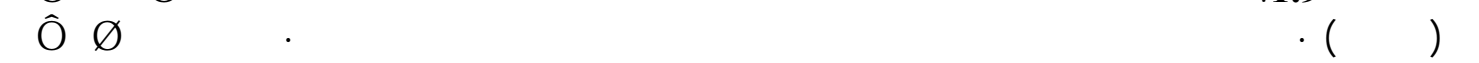

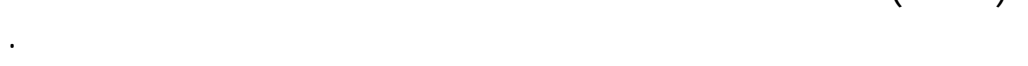




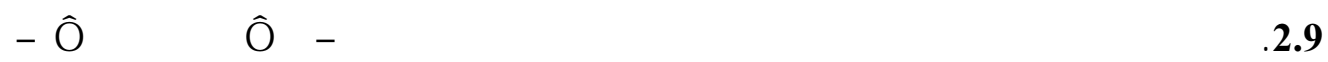

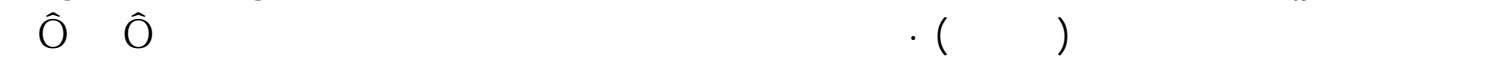

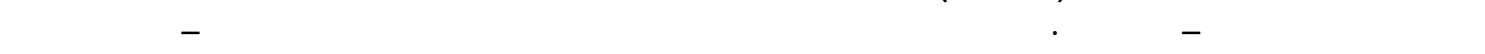

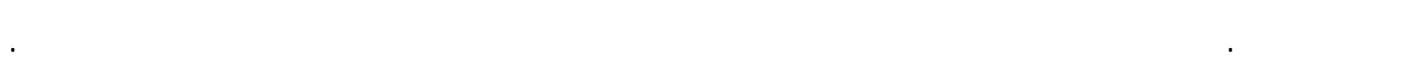

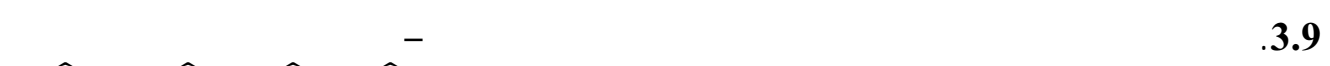

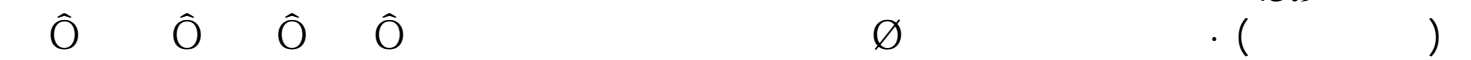
Fo aroứ̛́s

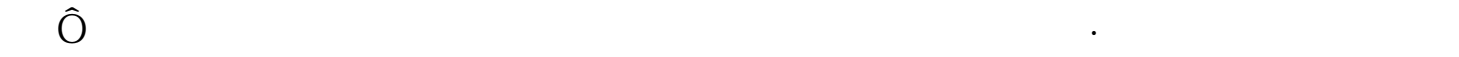

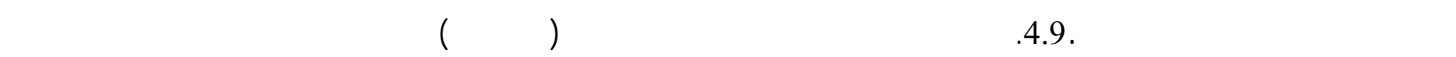

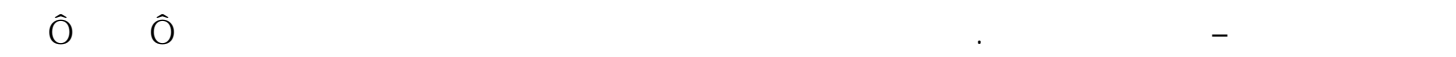

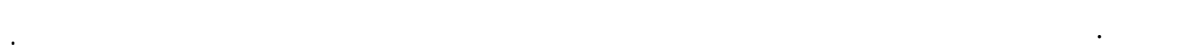

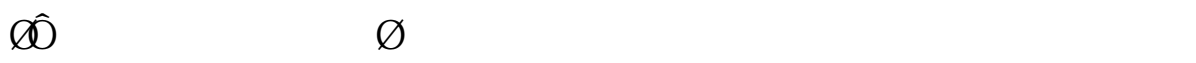

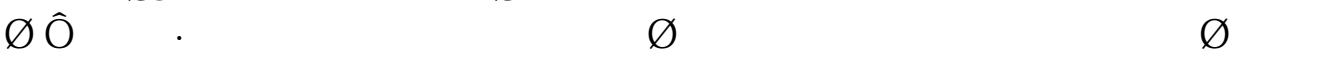

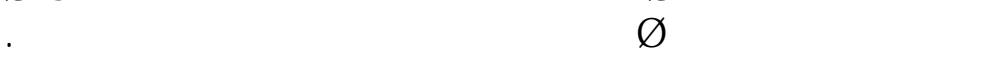

\section{Ibỡo}

1. Conrad, Ulrich, Programmers and Manifestoes on $\mathbf{2 0}^{\text {th }}$ century Architecture, Lund Humphvies, (2000).

2. Lang, Hohn, Greating Architectural theory: The Role of Behavioral Sciences in Environmental design, VNR, 1987.

3. Rapoport, Amos, Culture and urban order; in the city in cultural context, Allen Unwin, (1984).

4. Rauf, Laith, Tradition and continuity in the Modern Iraqi House, in (UR), (2003).

5. Schulz, Christian Norbeg, Intention in Architecture, Scandinavian University books, Osto, Norway, (1996).

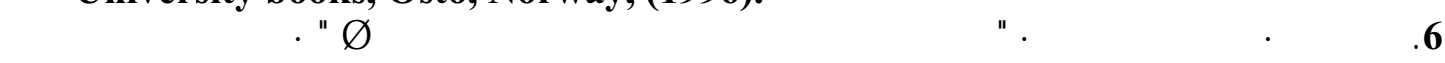

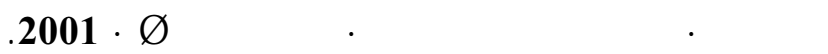

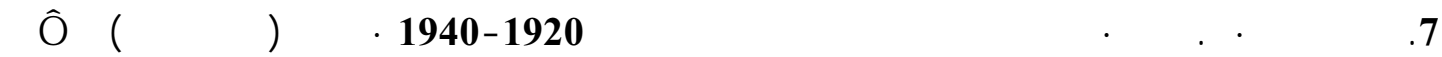
$.1980 \square 5$

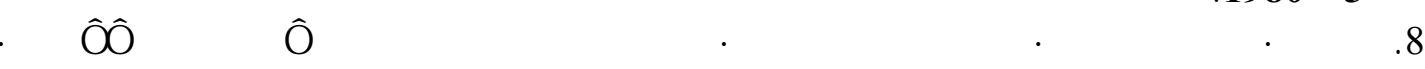

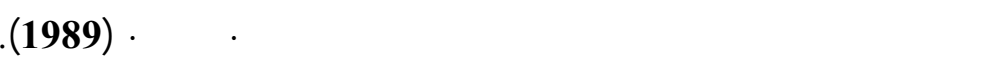




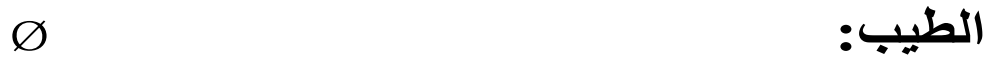

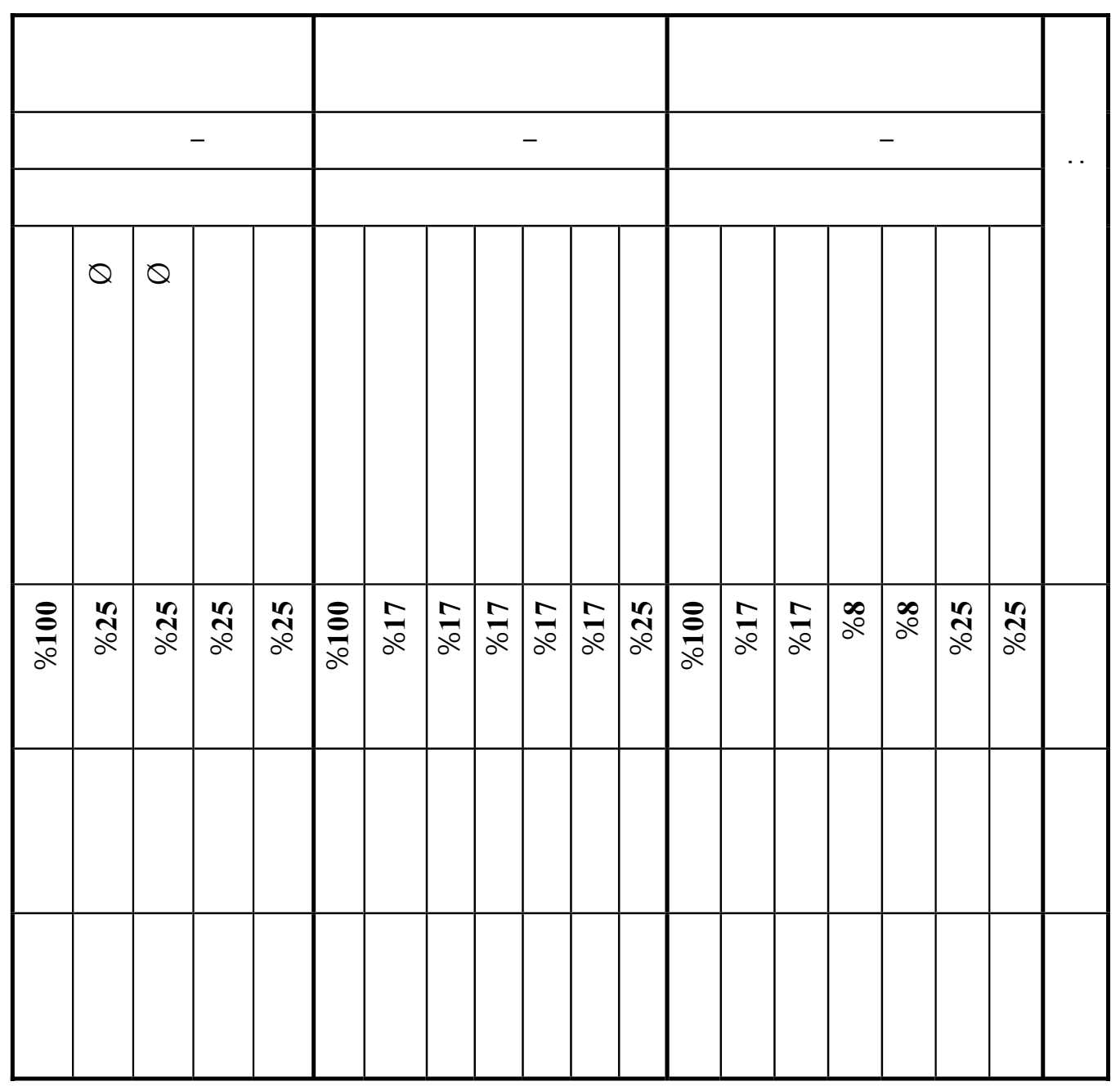

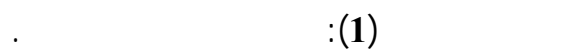

\begin{tabular}{|c|c|c|c|}
\hline$\tilde{\mathbf{U}} \mathbf{E} \mathbf{E}$ & 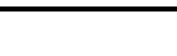 & 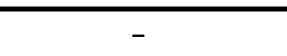 & 3/6 \\
\hline & & & \\
\hline$\tilde{\mathbf{U}} \mathbf{E} \mathbf{K E}$ & 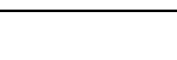 & r) & \\
\hline & & & \\
\hline$\tilde{\mathbf{W}}=\mathbf{R E}$ & 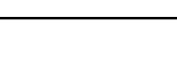 & 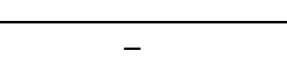 & \\
\hline & & & \\
\hline & & & \\
\hline
\end{tabular}

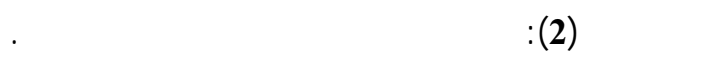




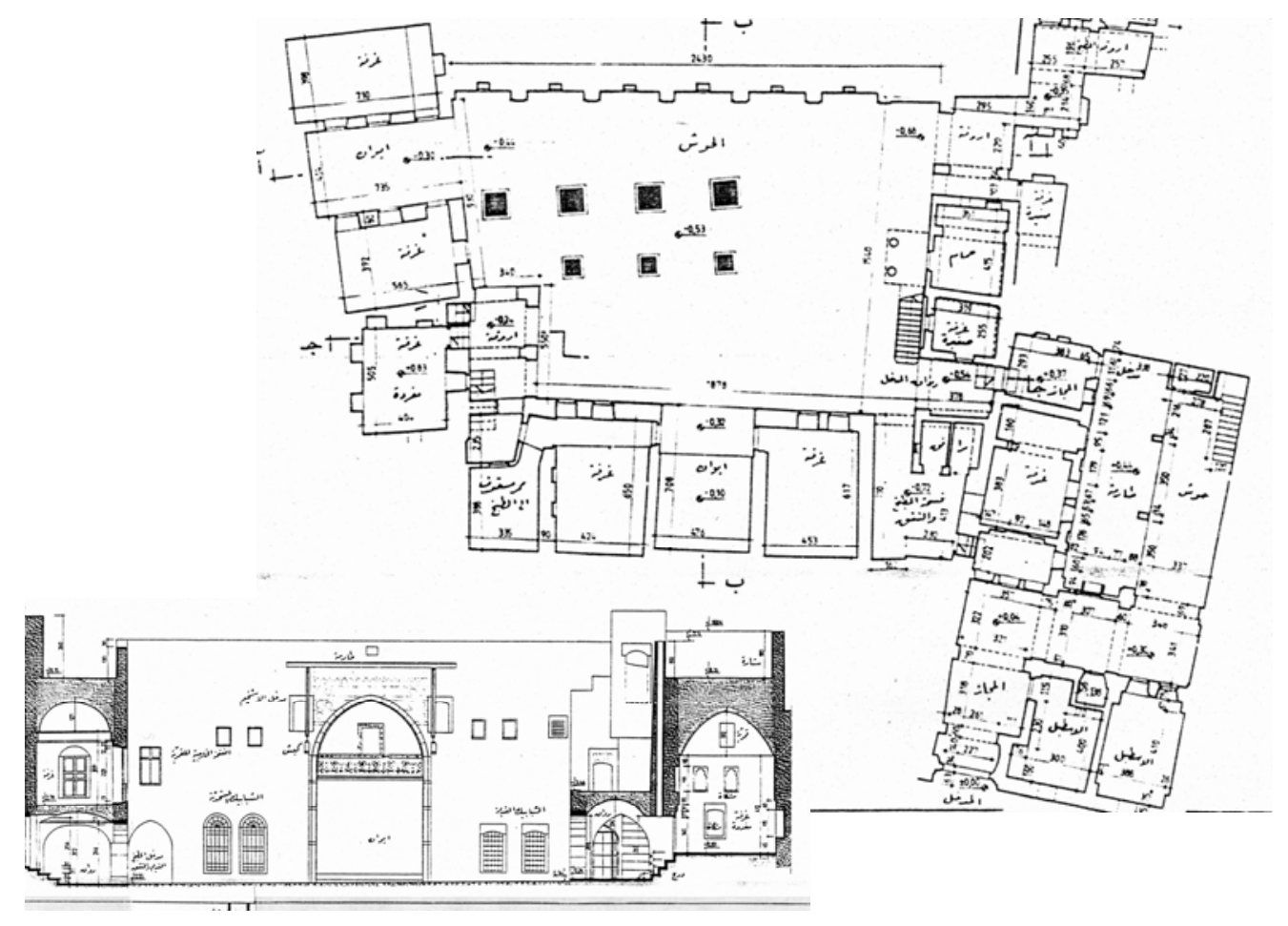

If
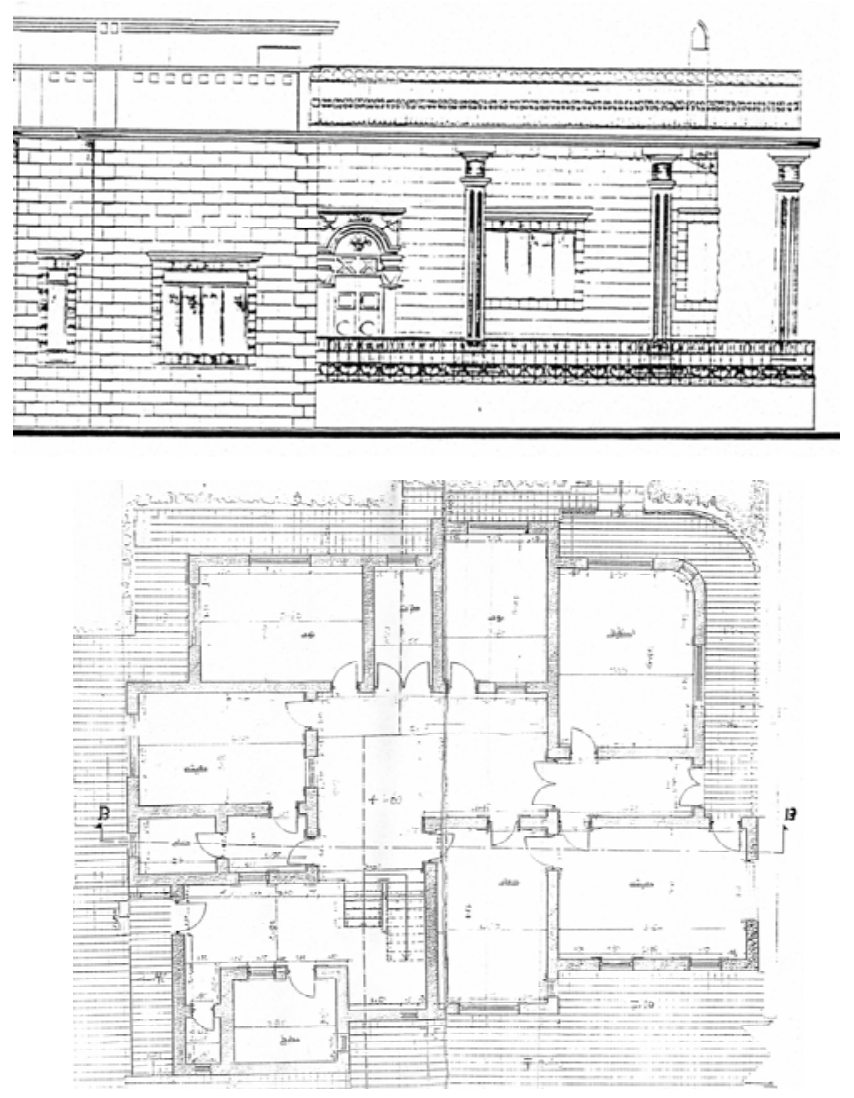

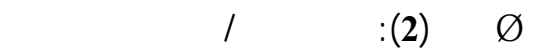



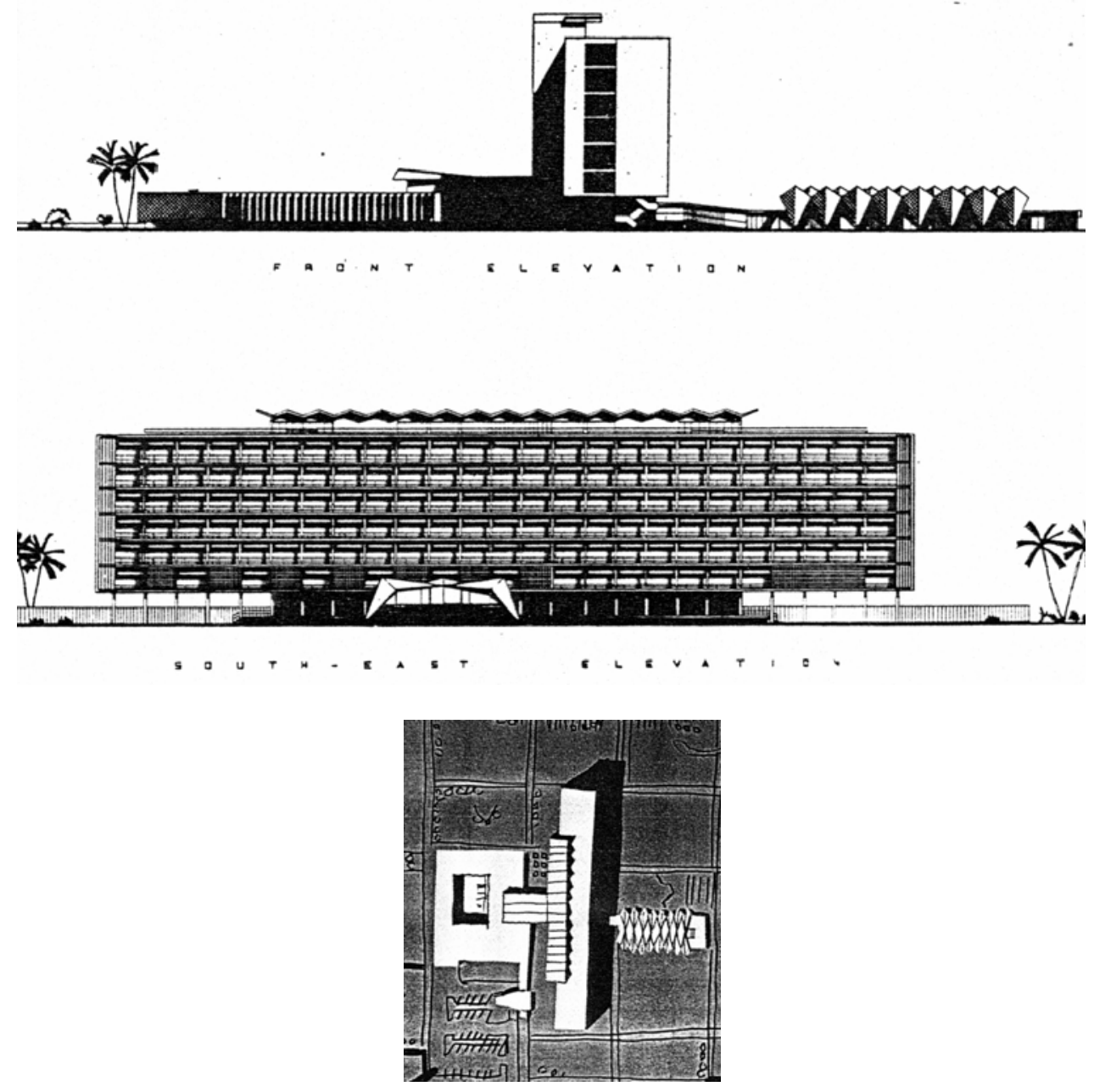

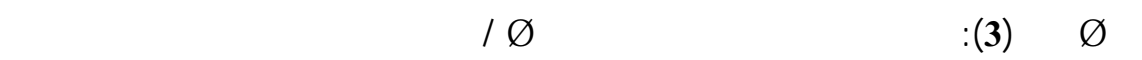

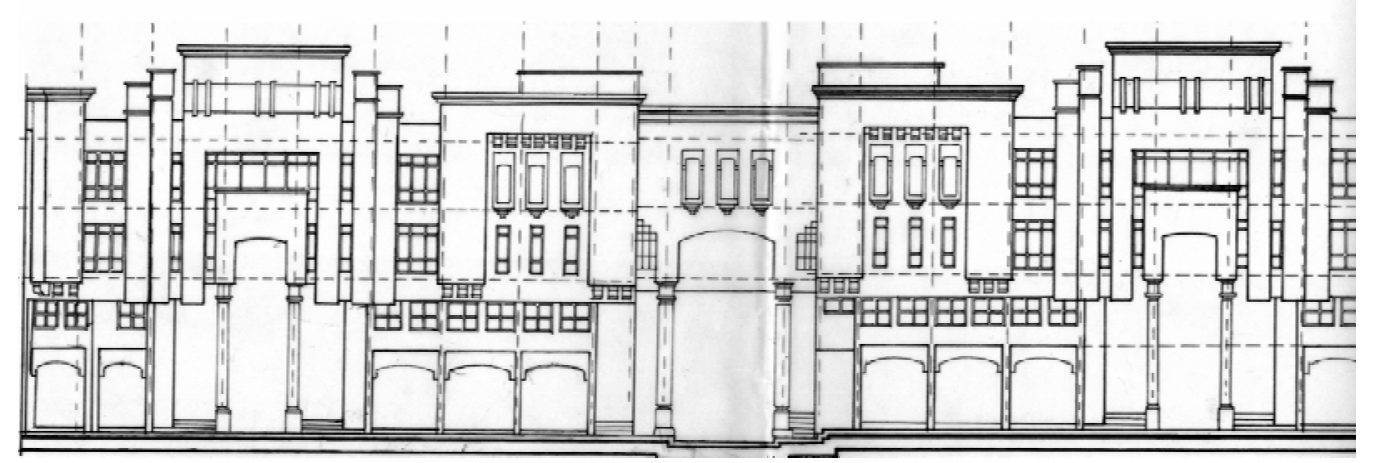

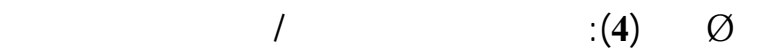

